\title{
Article
}

\section{The FDA-Approved Antiviral Raltegravir Inhibits Fascin1-Dependent Invasion of Colorectal Tumor Cells In Vitro and In Vivo}

\author{
Begoña Alburquerque-González ${ }^{1,+}{ }^{\oplus}$, Ángel Bernabé-García ${ }^{2,+}$, Manuel Bernabé-García $\left.{ }^{3}{ }^{(}\right)$, Javier Ruiz-Sanz ${ }^{4}(\mathbb{D}$, \\ Fernando Feliciano López-Calderón ${ }^{1}$, Leonardo Gonnelli ${ }^{5,6}{ }^{\circledR}$, Lucia Banci ${ }^{5,6}$ [D, Jorge Peña-García ${ }^{7}$, \\ Irene Luque ${ }^{4}{ }^{\circledR}$, Francisco José Nicolás ${ }^{2}{ }^{\circledR}$, María Luisa Cayuela-Fuentes ${ }^{3}$, Enrico Luchinat ${ }^{5,8}{ }^{\circ}$, \\ Horacio Pérez-Sánchez ${ }^{7}$ (D), Silvia Montoro-García ${ }^{9, *(D)}$ and Pablo Conesa-Zamora ${ }^{10, *(D)}$
}

Citation: Alburquerque-González, B.; Bernabé-García, Á.; Bernabé-García, M.; Ruiz-Sanz, J.; López-Calderón, F.F.; Gonnelli, L.; Banci, L.; Peña-García, J.; Luque, I.; Nicolás, F.J.; et al. The FDA-Approved Antiviral Raltegravir Inhibits Fascin1-Dependent Invasion of Colorectal Tumor Cells In Vitro and In Vivo. Cancers 2021, 13, 861. https://doi.org/10.3390/cancers13040861

Academic Editor: Serge Roche

Received: 28 January 2021

Accepted: 15 February 2021

Published: 18 February 2021

Publisher's Note: MDPI stays neutral with regard to jurisdictional claims in published maps and institutional affiliations.

Copyright: (c) 2021 by the authors. Licensee MDPI, Basel, Switzerland. This article is an open access article distributed under the terms and conditions of the Creative Commons Attribution (CC BY) license (https:/ / creativecommons.org/licenses/by/ $4.0 /)$.
1 Department of Pathology and Histology, Campus de los Jerónimos, UCAM Universidad Católica San Antonio de Murcia, s/n, 30107 Murcia, Spain; balburquerque2@ucam.edu (B.A.-G.); fflopez@alu.ucam.edu (F.F.L.-C.)

2 Laboratorio de Regeneración, Oncología Molecular y TGF-ß, Biomedical Research Institute of Murcia (IMIB-Arrixaca), Carretera Madrid-Cartagena, El Palmar, 30120 Murcia, Spain; angel.bernabe@imib.es (Á.B.-G.); franciscoj.nicolas2@carm.es (F.J.N.)

3 Telomerase, Cancer and Aging Group, Biomedical Research Institute of Murcia (IMIB-Arrixaca), 30120 Murcia, Spain; manuel.bernabe@carm.es (M.B.-G.); marial.cayuela@carm.es (M.L.C.-F.)

4 Department of Physical Chemistry, Institute of Biotechnology and Excellence Research Unit of "Chemistry Applied to Biomedicine and the Environment, Spain Campus Fuentenueva s/n, University of Granada, 18071 Granada, Spain; jruizs@ugr.es (J.R.-S.); iluque@ugr.es (I.L.)

5 CERM-Magnetic Resonance Center, Università degli Studi di Firenze, Via Luigi Sacconi 6, 50019 Sesto Fiorentino, Italy; gonnelli@cerm.unifi.it (L.G.); banci@cerm.unifi.it (L.B.); eluchinat@cerm.unifi.it (E.L.)

6 Dipartimento di Chimica, Università degli Studi di Firenze, Via della Lastruccia 3, 50019 Sesto Fiorentino, Italy

7 Structural Bioinformatics and High Performance Computing (BIO-HPC) Research Group, Campus de los Jerónimos, s/n, UCAM Universidad Católica San Antonio de Murcia, Guadalupe, 30107 Murcia, Spain; jpena@ucam.edu (J.P.-G.); hperez@ucam.edu (H.P.-S.)

8 Consorzio per lo Sviluppo dei Sistemi a Grande Interfase-CSGI, Via della Lastruccia 3, 50019 Sesto Fiorentino, Italy

9 Cell Culture Lab, Facultad de Ciencias de la Salud, Campus de los Jerónimos, s/n, UCAM Universidad Católica San Antonio de Murcia, Guadalupe, 30107 Murcia, Spain

10 Laboratory Medicine Department, Group of Molecular Pathology and Pharmacogenetics, Biomedical Research Institute from Murcia (IMIB), Hospital Universitario Santa Lucía, c/Mezquita sn, 30202 Cartagena, Spain

* Correspondence: smontoro@ucam.edu (S.M.-G.); pablo.conesa@carm.es (P.C.-Z.); Tel.: +34-9681-286-02 (Ext. 951615) (P.C.-Z.)

+ These authors contributed equally to this paper.

Simple Summary: Colorectal cancer (CRC) is the third leading cause of cancer-related deaths worldwide. Serrated adenocarcinoma (SAC) has been recently recognized by the WHO as a histological CRC with bad prognosis. Consistent with previous evidence, our group identified Fascin1 as a protein directly related to the invasiveness of tumor cells, overexpressed and positively correlated with worse survival in various carcinomas, including SAC. Therefore, Fascin1 has emerged as an ideal target for cancer treatment. In the present study, virtual screening has been carried out from a library of 9591 compounds, thus identifying the FDA-approved anti-retroviral raltegravir (RAL) as a potential Fascin1 blocker. In vitro and in vivo results show that RAL exhibits Fascin1-binding activity and Fascin1-dependent anti-invasive and anti-metastatic properties against CRC cells both in vitro and in vivo.

Abstract: Background: Fascin1 is the key actin-bundling protein involved in cancer invasion and metastasis whose expression is associated with bad prognosis in tumor from different origins. Methods: In the present study, virtual screening (VS) was performed for the search of Fascin1 inhibitors and RAL, an FDA-approved inhibitor of human immunodeficiency virus-1 (HIV-1) integrase, was 
identified as a potential Fascin1 inhibitor. Biophysical techniques including nuclear magnetic resonance (NMR) and differential scanning fluorimetry (DSF) were carried out in order to confirm RAL as a Fascin1 blocker. The effect of RAL on actin-bundling activity Fascin1 was assessed by transmission electron microscopy (TEM), immunofluorescence, migration, and invasion assays on two human colorectal adenocarcinoma cell lines: HCT-116 and DLD-1. In addition, the anti-metastatic potential of RAL was in vivo evaluated by using the zebrafish animal model. Results: NMR and DSF confirmed in silico predictions and TEM demonstrated the RAL-induced disorganization of the actin structure compared to control conditions. The protrusion of lamellipodia in cancer cell line overexpressing Fascin1 (HCT-116) was abolished in the presence of this drug. By following the addition of RAL, migration of HCT-116 and DLD-1 cell lines was significantly inhibited. Finally, using endogenous and exogenous models of Fascin1 expression, the invasive capacity of colorectal tumor cells was notably impaired in the presence of RAL in vivo assays; without undesirable cytotoxic effects. Conclusion: The current data show the in vitro and in vivo efficacy of the antiretroviral drug RAL in inhibiting human colorectal cancer cells invasion and metastasis in a Fascin1-dependent manner.

Keywords: Fascin1; raltegravir; migrastatin; invasion; migration; zebrafish xenograft; colorectal cancer

\section{Introduction}

Colorectal cancer (CRC) is the third leading cause of cancer-related deaths worldwide [1]. Serrated adenocarcinoma (SAC) has been recently recognized as a new subtype of CRC [2]. Several drugs are currently being used for the cancer treatment following different mechanisms of action. Therapeutic strategies include drugs targeting specific proteins found altered in cancer cells thus decreasing their growth and survival rate. Hence, during the past few decades, identifying novel chemical compounds that modulate cellular targets has emerged as an exciting approach for the development of selective anticancer treatments. However, given the fact that SAC, compared to conventional colorectal carcinoma, exhibits a higher frequency of $K R A S$ or $B R A F$ mutations and that most SACs are microsatellite stable $[3,4]$, this CRC subtype is especially resistant to targeted therapy such as anti-EGFR and immune checkpoint inhibitors, respectively. Therefore, there is an urgent need to count with a targeted molecular therapy for treating SAC [5].

Consistent with previous evidence, Fascin1 has been identified as an actin-bundling protein, a key molecule in the invasiveness of tumor cells which is overexpressed and positively correlated with worse survival in various carcinomas, including SAC [6]. Numerous studies have implicated Fascin1 as a biomarker for aggressive carcinomas [6,7]. It is generally believed that Fascin1 plays a mechanical role in driving tumor-cell migration, invasion, and metastasis by facilitating actin-based membrane protrusions such as filopodia and lamellipodia, whereas it is not expressed by normal epithelia [8,9]. Therefore, Fascin1 has emerged as an ideal target for cancer treatment $[7,10]$ and the discovery of Fascin1 blockers deserves further research [11]. Currently, Fascin1 inhibitors such as migrastatin (MGS) and N-(1-(4-(trifluoromethyl) benzyl)-1H-indazol-3-yl) furan-2-carboxamide (G2) analogues such as 4-methyl-N-(1-(4-(trifluoromethyl) benzyl)-1H-indazol-3- yl)isoxazole5-carboxamide (NP-G2-029) have been tested in vitro and in vivo as they are likely to suppress tumor-cell migration by inhibiting the actin-bundling activity [12-14].

Recent increased knowledge in molecular sciences and bioinformatics is currently contributing to the discovery of new potential drug targets. This has changed the paradigms of anticancer drug discovery toward molecularly targeted therapeutics. Our previous data further illustrates the use of this therapeutic targeted approach [12]. In this study, our group performed virtual screening (VS) for the search of anti-Fascin1 compounds, and found that RAL, an FDA-approved inhibitor of human immunodeficiency virus-1 (HIV-1) integrase, showed Fascin1-binding activity. Additionally, we show that RAL displays important inhibitory effects on lamellipodium formation, migration, and invasion 
in different colorectal cancer cell lines. Moreover, RAL treatment resulted in significant reduction of invasion of DLD-1 overexpressing Fascin1 and HCT-116 in zebrafish larvae xenografts. Our results further indicate the use of RAL as a potential treatment for CRC based on in silico molecular drug-target identification.

\section{Materials and Methods}

\subsection{Virtual Screening}

Molecular docking-based VS calculations using Autodock Vina [15] were applied to propose FDA compounds repurposed as Fascin1 inhibitors. For such a purpose, the structural model for Fascin1 was extracted from the crystal structure of protein data bank (PDB) with code 6B0T and converted to PDBQT format with MGLTOOLS (http: / / mgltools.scripps.edu, accessed on 7 January 2021 at 12:30) using default parameters. Ligand cocrystalized with Fascin1 in 6B0T (NP-G2-029) was also converted to PDBQT format. Next, this protein model was screened with Autdock Vina against a subset of the DrugBank library (version 5.0; of 9591 compounds, including 2037 approved by the American FDA, 96 nutraceuticals, and 6000 experimental) and compound NP-G2-029.

\subsection{Molecular Dynamics}

Molecular dynamics (MD) was applied to selected compound from VS calculations and NP-G2-029 in order to study the dynamics evolution of selected Fascin1-ligand complexes and check stability of the ligands in the binding site. MD simulations were carried out with the GPU version of Desmond included in the Maestro suite 2019.4 (Schrödinger LLC), on a server with a NVIDIA QUADRO PRO 5000. Complexes were solvated in an aqueous environment in a cubic box with a minimal distance of $10 \AA$ between each ligand and the box boundary (for periodic boundary conditions). Afterwards, systems were neutralized in $0.15 \mathrm{M} \mathrm{NaCl}$ and the OPLS3 force field and the TIP3P-TIP4P water models were employed [16]. Initially, the systems were setup in the NPT ensemble, and pressure was controlled using the Martyna-Tobias-Klein methodology, and the Nose-Hoover thermostat was employed to keep the system near 310K. Production of MD trajectories were extended to 100 nanoseconds (ns) per system. Resulting MD trajectories were analyzed in terms of averaged protein-ligand interactions over time and in terms of the root-mean-square deviation (RMSD) of fluctuations.

\subsection{Structural Comparison}

The Pocketalign web server (http://proline.physics.iisc.ernet.in/pocketalign/, accessed on 7 January 2021) was used for the alignment of the binding pockets of the structural models for proteins Fascin1 (PDB code 6B0T) and Aldolase A (PDB code 3B8D). After performing the structural alignment of these defined substructures Pocketalign reports information about three-dimensional matching between residue types.

\subsection{Compound Purchase-Chemistry}

Ralteagravir (RAL) potassium (C20H20FKN6O5; PM 482.51) was purchased from Sigma Aldrich. Migrastatin (MGS) was synthesized by AnalytiCon Discovery (NP-006108) and provided by MolPort (Riga, Latvia).

\subsection{Recombinant Fascin1 Expression and Purification}

Recombinant Fascin1 for in vitro studies was expressed in BL21-gold (DE3) E. coli strain transformed with the pGEX-6P-2A plasmid encoding the full-length human Fascin1 (UniProt Q16658) fused at the N-terminus with glutathione-S-transferase (GST) and the human rhinovirus 3C protease cleavage site. This construct was kindly provided by Dr. S. Windhorst from University Medical Center Hamburg-Eppendorf, Hamburg, Germany). Cells were grown at $37^{\circ} \mathrm{C}$ in Terrific Broth (TB) medium previously inoculated with a preculture of transformed cells grown overnight at $28^{\circ} \mathrm{C}$ in TB. Protein expression was induced at $\mathrm{OD}_{600}=0.8$ with $0.5 \mathrm{mM}$ IPTG and carried out for $5 \mathrm{~h}$ at $37^{\circ} \mathrm{C}$. The cells were 
centrifuged at $4{ }^{\circ} \mathrm{C}, 5000 \times g$ for $15 \mathrm{~min}$, resuspended in binding buffer $(20 \mathrm{mM}$ Sodium phosphate buffer, $150 \mathrm{mM} \mathrm{NaCl}, \mathrm{pH}$ 7.3), and lysed by ultrasonication in ice bath and centrifuged for $40 \mathrm{~min}$ at $4{ }^{\circ} \mathrm{C}, 6000 \mathrm{~g}$. Fascin 1 was purified by affinity chromatography. The supernatant was loaded at $2 \mathrm{~mL} / \mathrm{min}$ in a $5 \mathrm{~mL}$ GSTrap FF (Cytiva) column preequilibrated with binding buffer, further washed with $10 \mathrm{CV}$ of binding buffer and $10 \mathrm{CV}$ of cleavage buffer (50 mM Tris- $\mathrm{HCl}, 150 \mathrm{mM} \mathrm{NaCl}, 1 \mathrm{mM}$ EDTA, $1 \mathrm{mM}$ dithiothreitol, $\mathrm{pH}$ 7.5). Proteolytic cleavage was performed on-column by loading a PreScission protease stock solution (Cytiva) diluted 1/25 in cleavage buffer according to the manufacturer protocol and incubating at $4{ }^{\circ} \mathrm{C}$ for $4 \mathrm{~h}$. Fascin 1 was eluted with $3 \mathrm{CV}$ of cleavage buffer (5 mL/min), concentrated with a centrifugal concentrator (MWCO $30 \mathrm{kDa}$ ) at $4000 \times g$, $\mathrm{T}<20^{\circ} \mathrm{C}$, and quantified by absorption at $280 \mathrm{~nm}$ using a predicted molar extinction coefficient $\varepsilon_{280}=68,465 \mathrm{M}^{-1} \mathrm{~cm}^{-1}$. A protein yield of $\sim 40 \mathrm{mg} / \mathrm{L}$ was estimated.

\subsection{Thermofluor and Fluorescence Titration}

Differential Scanning Fluorimetry (Thermofluor) assays were performed using a Biorad C1000 Touch Thermal Cycler CFX96 RT-PCR system in a 96-well format. Twentyfive $\mu \mathrm{L}$ reaction mixtures were set up containing $2 \mu \mathrm{M}$ Fascin1 (Hypermol, Bielefeld, Germany) in $20 \mathrm{mM}$ Hepes, $150 \mathrm{mM} \mathrm{NaCl}, 1 \mathrm{mM}$ DTT, and 5\% sucrose at $\mathrm{pH} 7.4$, in the presence of SYPRO Orange (1000-fold dilution from the commercial stock (Invitrogen, Carlsbad, CA, USA). The indicated compounds, prepared at $10 \mathrm{mM}$ in DMSO, were added to each well to a diluted final concentration of $1 \mathrm{mM}$ and $10 \%$ DMSO. Three replicates per compound together with six internal controls, containing only free protein in $10 \%$ DMSO, were included in the 96-well plates. The PCR plates were covered and subsequently shaken, centrifuged, incubated for $2 \mathrm{~min}$ at $20^{\circ} \mathrm{C}$ inside the RT-PCR machine, and heated from 20 to $100{ }^{\circ} \mathrm{C}$ at a $1{ }^{\circ} \mathrm{C} / \mathrm{min}$ scan-rate. Fascin 1 thermal denaturation profiles were obtained recording the fluorescence intensity for the FAM, HEX, and T-Red predefined filters. The derivative of the fluorescence curve was used to determine the Tm. Changes in Tm associated to ligand binding were estimated taking the average Tm value derived from the free protein internal controls. Fascin 1 was extensively dialyzed against the appropriate buffer prior to each titration experiment. Fascin 1 concentration was determined by measuring absorbance at $280 \mathrm{~nm}$ using an extinction coefficient of $67,840 \mathrm{~cm}^{-1} \cdot \mathrm{M}^{-1}$.

Fluorescence titration experiments were performed in a Cary Eclipse spectrofluorometer (Varian Inc., Palo Alto, CA, USA). Fascin1 solution at $15 \mu \mathrm{M}(14.7 \mu \mathrm{M})$ was titrated with each compound by adding increasing volumes of concentrated solutions. Emission spectra were recorded between 307 and $500 \mathrm{~nm}$ at $25^{\circ} \mathrm{C}$ in $10 \%$ DMSO, $100 \mathrm{mM} \mathrm{NaCl}$, $20 \mathrm{mM}$ Hepes, pH 7.4, with the excitation wavelength fixed at $280 \mathrm{~nm}$. Binding isotherms were generated using the changes in spectral area and fitted using ORIGIN 7.0 (Microcal Inc. Malvern panalytical, Worcerstershire, UK) to a one-site equilibrium binding model, according to the following Equation (1):

$$
F=F_{f}+\left(F_{b}-F_{f}\right) \cdot \frac{\left(P_{T}+L_{T}+K_{d}\right)-\sqrt{\left(P_{T}+L_{T}+K_{d}\right)^{2}-4 \cdot P_{T} \cdot L_{T}}}{2 \cdot P_{T}}
$$

where $F_{f}$ and $F_{b}$ are the fluorescence signal of free and bound Fascin 1 and $P_{T}$ and $L_{T}$ are the total protein and ligand concentration, respectively, at each addition point.

\subsection{Ligand-Observed NMR}

Saturation transfer difference (STD) and WaterLOGSY (WL) NMR experiments were recorded at $298 \mathrm{~K}$ with a Bruker Avance NEO $700 \mathrm{MHz}$ (Bruker Corp., Billerica, MA, USA) equipped with a $5 \mathrm{~mm}$ cryogenically cooled TCI probe. Stock solutions of each ligand were prepared by dissolving the powder in $\mathrm{d}_{6}$-DMSO to a final concentration of $50 \mathrm{mM}$. For the NMR experiments, a protein:ligand ratio of 1:50 was chosen, that is within the working range of both STD and WL experiments. Protein NMR samples contained $10 \mu \mathrm{M}$ 
of Fascin 1 and $500 \mu \mathrm{M}$ of each ligand in NMR buffer (phosphate buffered saline (PBS, Gibco), pH $7.4+10 \% \mathrm{D}_{2} \mathrm{O}$ ). Control samples contained $10 \mu \mathrm{M}$ of each ligand dissolved in NMR buffer. The final DMSO concentration in all NMR samples was $1 \%$. For each sample, a $1 \mathrm{D}^{1} \mathrm{H}$ reference spectrum, a STD and a WL experiment were recorded. STD spectra (stddiffesgp. 3 pulse program [17] were acquired with 512 scans with on-resonance irradiation at $0 \mathrm{ppm}$ and off-resonance irradiation at $-40 \mathrm{ppm}$. A train of 40 Gaussian shaped pulses of $50 \mathrm{~ms}$ was used, for a total saturation time of $2 \mathrm{~s}$. Final STD spectra were obtained by internal subtraction of the saturated spectrum from the reference spectrum. WL spectra (ephogsygpno.2 pulse program [18] were acquired with 1024 scans with a $7.5 \mathrm{~ms}$ selective $180^{\circ}$ Gaussian shaped pulse at the water signal frequency and a CLEANEX spinlock time of $30 \mathrm{~ms}$. For both STD and WL, a spectral width of $16 \mathrm{ppm}, 2.0$ s relaxation delay, 16384 data points for acquisition, and 65536 points for transformation were used. The spectra were processed with the Bruker TOPSPIN software by applying a $1 \mathrm{~Hz}$ exponential line broadening.

\subsection{Transmission Electron Microscopy Detection}

Transmission electron microscopy (TEM) was assessed, following previous methodology by Jansen et al., 2011 [19]. Briefly, purified actin $(21 \mu \mathrm{M})$ was polymerized according to the protocol from the Actin-Binding Protein Biochem Kit ${ }^{\mathrm{TM}}$ Muscle Actin (Cytoskeleton Inc., Denver, CO, USA) and then incubated with human recombinant Fascin1 (Hypermol, Bielefeld, Germany) (molar ratio 1:1) for $30 \mathrm{~min}$ at room temperature. Fascin1 was previously incubated for $2 \mathrm{~h}$ at room temperature with $0.1 \%$ DMSO (control), $100 \mu \mathrm{M}$ MGS, $10 \mu \mathrm{M}$ imipramine, $10 \mu \mathrm{M}$ G2 compound, or $30 \mu \mathrm{M}$ RAL. The samples were directly adsorbed onto 200 mesh copper grids for $30 \mathrm{sec}$, blotted to remove excess solution, washed twice with distilled water, and negatively stained with $1 \%(w / v)$ uranyl acetate for $30 \mathrm{~s}$, blotted, and dried again. The TEM study of actin filaments and Fascin1-actin bundles was performed on a PHILIPS TECNAI 12 transmission electron microscope (FEI, Osaka, Japan) at an accelerating voltage of $80 \mathrm{kV}$ and a magnification up to 135,000X. Images were captured on a coupled device camera (Megaview III). The numbers of filaments per bundle were counted manually in 20 pictures/condition and statistically analyzed (Mann-Whitney test).

\subsection{Cell Culture}

Two human colorectal adenocarcinoma cell lines, HCT-116 and DLD-1, and HaCaT (human spontaneously immortalized keratinocyte) [20] cells were obtained from the American Type Culture Collection (ATCC, Rockville, MD, USA). All cell lines were cultivated using standard medium: high-glucose Dulbecco's Modified Eagle's Medium (DMEM) supplemented with $10 \%$ heat-inactivated fetal bovine serum (FBS), $50 \mathrm{U} / \mathrm{mL}$ penicillin, and $50 \mu \mathrm{g} / \mathrm{mL}$ streptomycin (all from Sigma Aldrich Chemical Co., Darmstadt, Germany), at $37^{\circ} \mathrm{C}, 5 \% \mathrm{CO}_{2}$, and $95 \%$ humidified atmosphere. Subculturing was performed when cells reached 90\% confluence. Cell RNA extraction and qPCR for Fascin1 expression quantification was performed as previously described [12]. In vivo assays, the human colorectal carcinoma cells were genetically overexpressed (DLD-1) for Fascin1, as previously reported by our group [13].

\subsection{Cell Viability Assay}

Exponentially growing cells were plated in flat-bottomed 96-well plates (Nunc, Roskilde, Denmark) in triplicate (1500 cells/well). Cells were treated with a series of concentrations from $5 \mu \mathrm{M}$ to $100 \mu \mathrm{M}$ of either MGS or RAL up to 3 days (24, 48 and $72 \mathrm{~h}$ ) in a $5 \%$ $\mathrm{CO}_{2}$ humidified atmosphere. Control cells were treated with a drug carrier, control $(0.1 \%$ DMSO). Cells were assayed for viability as follows: In brief, Dulbecco's phosphate-buffered saline (DPBS) supplemented with $1.9 \mathrm{mg} / \mathrm{mL}$ tetrazolium (MTT) $\mathrm{pH} 7.2$ was added to the cells ( $30 \mu \mathrm{L} /$ well). After incubation at $37^{\circ} \mathrm{C}$ for $4 \mathrm{~h}$, the medium was carefully aspirated. The formazan crystals were dissolved in $200 \mu \mathrm{L}$ DMSO for $30 \mathrm{~min}$, and the absorbance was 
read in a microtiter plate reader at $570 \mathrm{~nm}$ and $620 \mathrm{~nm}$ as reference. Results were calculated as cell viability (\%) = average optical density (O.D.) of wells/average O.D. of control wells.

\subsection{Cell-Migration Assay}

Cell migration was studied using HCT-116 and DLD-1 cell lines by performing a scratch-wound healing assay in standard medium supplemented with 5\% FBS. Typically, 50,000 cells were plated in low $35 \mathrm{~mm}$ dishes with culture inserts following manufacturer instructions (Ibidi, Martinsried, Germany). After appropriate cell attachment and monolayer formation (around $24 \mathrm{~h}$ ), inserts were removed with sterile forceps to create a wound field of approximately $500 \mu \mathrm{m}$. Detached cells were gently removed with DPBS before the addition of drugs. Confluent cells were incubated in one of the following treatments: control (0.1\% DMSO), $100 \mu \mathrm{M}$ MGS, or $30 \mu \mathrm{M}$ RAL. Cells were then placed in a cell-culture incubator and they were allowed to migrate. At 0,4 , and $7 \mathrm{~h}$ (linear growth phase), 10 fields of the injury area were photographed with an inverted phase contrast microscope using $10 \times$ magnification. For each time point, the area uncovered by cells was determined by Image J software (National Institute of Health, Bethesda, MD, USA). Each treatment was performed in triplicate.

The migration speed of the wound closure was given as the percentage of the recovered area at each time point, relative to the initially covered area $\left(\mathrm{t}_{0}\right)$. The velocity of wound closure $(\% / h)$ was calculated according to the following Equation (2):

$$
\text { Slope }\left(\% \frac{\text { area }}{\mathbf{h}}\right)=\frac{\left(\% \text { covered area } t_{x}\right)-\left(\% \text { covered area } t_{0}\right)}{\left(t_{x}-t_{0}\right)}
$$

Slopes are expressed as percentages relative to control conditions.

\subsection{Transwell Invasion Assay}

The invasive capacity of HCT-116 and transfected DLD-1 overexpressing Fascin1 was determined using Cytoselect TM 24 Well Cell Invasion Assay (Basement Membrane Colorimetric Format) with Matrigel ${ }^{\circledR}$ coated Transwell chambers ( $8 \mu \mathrm{m}$ pore size) (Cell Biolabs Inc., San Diego, CA, USA). In brief, cells $\left(1 \times 10^{6}\right)$ were resuspended in serum free medium with corresponding inhibitors and seeded into the upper chamber. Additionally, $500 \mu \mathrm{L}$ of standard medium was added to the well. After $24 \mathrm{~h}$ of incubation, cells that remained on the upper chamber were scraped away with a cotton swab, and the cells at the bottom side of the filter were eluted and quantified at an absorbance of $560 \mathrm{~nm}$.

\subsection{Wounding-Scratch Assay Immunofluorescence}

Round coverslips (Thermo Fisher, Waltham, MA, USA) were seeded in 6-well plate with either HCT-116 or HaCaT cells in standard medium. When cells reached $100 \%$ confluence, standard medium was replaced by a standard fresh-serum free medium. Then, wounding was performed by transversally dragging a sterilized razor blade on the central area of the coverslips. Just after wounding, cells were treated with either $100 \mu \mathrm{M}$ MGS, $30 \mu \mathrm{M}$ RAL, $10 \mathrm{ng} / \mathrm{mL}$ Epidermal Growth Factor (EGF), or $50 \mu \mathrm{M}$ of MEK inhibitor PD98059 (MEKi) (both from Sigma-Aldrich, St Louis, MO, USA), and cells were left for $24 \mathrm{~h}$. Afterwards, a subset of samples were fixed with Bouin solution (5\% Acetic acid, 9\% Formaldehyde and 0.9\% Picric acid, all from Sigma-Aldrich, St Louis, MO, USA) for Fascin1 protein staining. Alternatively, another subset of samples was fixed 15 min with $4 \%$ formaldehyde DPBS (PanReac AppliChem, Barcelona, Spain) for actin protein staining. Both types of fixations were DPBS washed three times and subsequently permeabilized for 15 min by using $0.3 \%$ Triton X-100/DPBS solution. Then, samples were incubated for $30 \mathrm{~min}$ in blocking solution $((0.3 \%$ bovine serum albumin (BSA)) (Santa Cruz Biotechnology, Heidelberg, Germany), 10\% FBS (Thermo Fisher Scientific, Waltham, MA, USA), 0.1\% Triton X-100 (Sigma-Aldrich, St Louis, MO, USA), and 5\% skimmed milk (Beckton Dickinson, Franklin Lakes, NJ, USA) in DPBS. Afterwards, samples were incubated for $1 \mathrm{~h}$ with anti-Fascin1 antibody (1/250) (55K-2 clone; Santa Cruz Biotechnology, Heidelberg, 
Germany). Samples were washed 3 times with 0.1\% Triton X-100/DPBS and incubated with the appropriate fluorescent-labelled secondary antibodies; for Fascin1 Alexa fluor 488-conjugated anti-mouse IgG (Molecular Probes, Thermo Fisher Scientific, Waltham, MA, USA) were used. To reveal actin and nuclei, samples were incubated with Alexa fluor 594-labelled phalloidin (Molecular Probes, Thermo Fisher Scientific, Waltham, MA, USA) and Hoechst 33258 (Fluka, Biochemika, Sigma-Aldrich, St Louis, MO, USA) for 30 min at room temperature in a wet chamber. All preparations were examined with a confocal microscope (LSM 510 META from ZEISS, Jena, Germany), and representative images were taken. Quantification of lamellipodia number was performed by counting elements in 20 random pictures per sample at $64 \times$ Student's $t$-test was applied for statistical analysis.

\subsection{Zebrafish Invasion and Metastasis Assays}

The colonization of zebrafish (Danio rerio) embryos by human cancer cells was performed as previously described [21]. Trypsinized, washed colorectal cancer cells were stained with fluorescent CM-Dil (Vybrant, Invitrogen), and 50-100 labeled cells were injected into the yolk sac of dechorionated zebrafish embryos. The viability of zebrafish embryos was assessed under $100 \mu \mathrm{M}$ MGSor $30 \mu \mathrm{M}$ RAL treatments and under the combined effect of compound treatment and tumor-cell injection. The evaluation criteria for embryos being colonized by human cancer cells was the presence of more than three cells outside the yolk sac. Metastasis assay was based on previous works by Fior et al., in which a metastatic potential assay on zebrafish was performed [22]. Transfected DLD-1 overexpressing Fascin1 and native HCT-116 cells were stained and xenografted as already mentioned. From the third day post-injection, larvae were fed with ZEBRAFEED by Sparos $(<100 \mu \mathrm{m})$, and treatments were changed daily. At day six post-injection, larvae were examined for monitoring tumor growth and invasion using a fluorescent microscope. The evaluation for metastasis potential by human cancer cells was the presence of cell colonies (dividing cells) outside the yolk sac. Fish with fluorescently labelled cells appearing outside the implantation area at $2 \mathrm{~h}$ post-injection were excluded from further analysis. All the fish were incubated at $35^{\circ} \mathrm{C}$ and analyzed with a SteReo Lumar V12 stereomicroscope equipped with an AxioCam MR5 camera (Carl Zeiss). The percentage of invasion and the presence of cell colonies were calculated by the researcher without previous knowledge of the experiment treatment conditions. The experiments were repeated in triplicate, obtaining an average value after four days post-xenograft (invasion assay) and six days post-xenograft (metastasis assay).

All the protocols in the manuscript comply with the recommendation, the approval of which was obtained from the participant institutions and in accordance with the ethical standards laid down in the 1964 Declaration of Helsinki and its later amendments.

\subsection{Data Analysis}

Data are expressed as mean \pm standard deviation (SD). Data were analyzed for statistical differences by the Student's t-test for paired and unpaired data after testing for normal distribution of the data. For in vitro experiments, Mann-Whitney statistical analysis was also performed. Differences were considered significant at an error probability of $p<0.05$. SPSS 21.0 software that was used for the rest of statistical analyses (SPSS, Inc., Chicago, IL, USA). One-way ANOVA (analysis of variance) with post hoc comparisons based on the Tukey's multiple comparisons test was applied.

\section{Results}

\subsection{Virtual Screening and Molecular Dynamics}

After VS calculations were finished, the top 20 compounds were selected in terms of docking score. In this list, NP-G2-029 was detected. Next, and after the visual inspection of resulting docking poses for these compounds, we prioritized ligands that shared the halogenated aromatic ring moiety of NP-G2-029 and the key interactions it establishes with neighboring residues, specifically pi-pi stacking with TRP101 and hydrophobic interactions 
with VAL134. We thus selected RAL (DrugBank code DB06817) following these criteria, and then we performed molecular dynamics (MD) for these two protein-ligand complexes. Both complexes yield RMSD fluctuation values less than $4 \AA$, which implies stability of both ligands in the studied Fascin1-binding site. In Figure 1, we can observe a 2D representation of the averaged protein-ligand interactions over the $100 \mathrm{~ns}$ trajectories, while the details can be checked in Appendix A (Figure A1). Both compounds share similar interaction patterns and RAL forms in addition to a dense network of hydrogen bonds with neighboring water molecules, which might be related to an increase of stability if we compare to NP-G2-029.
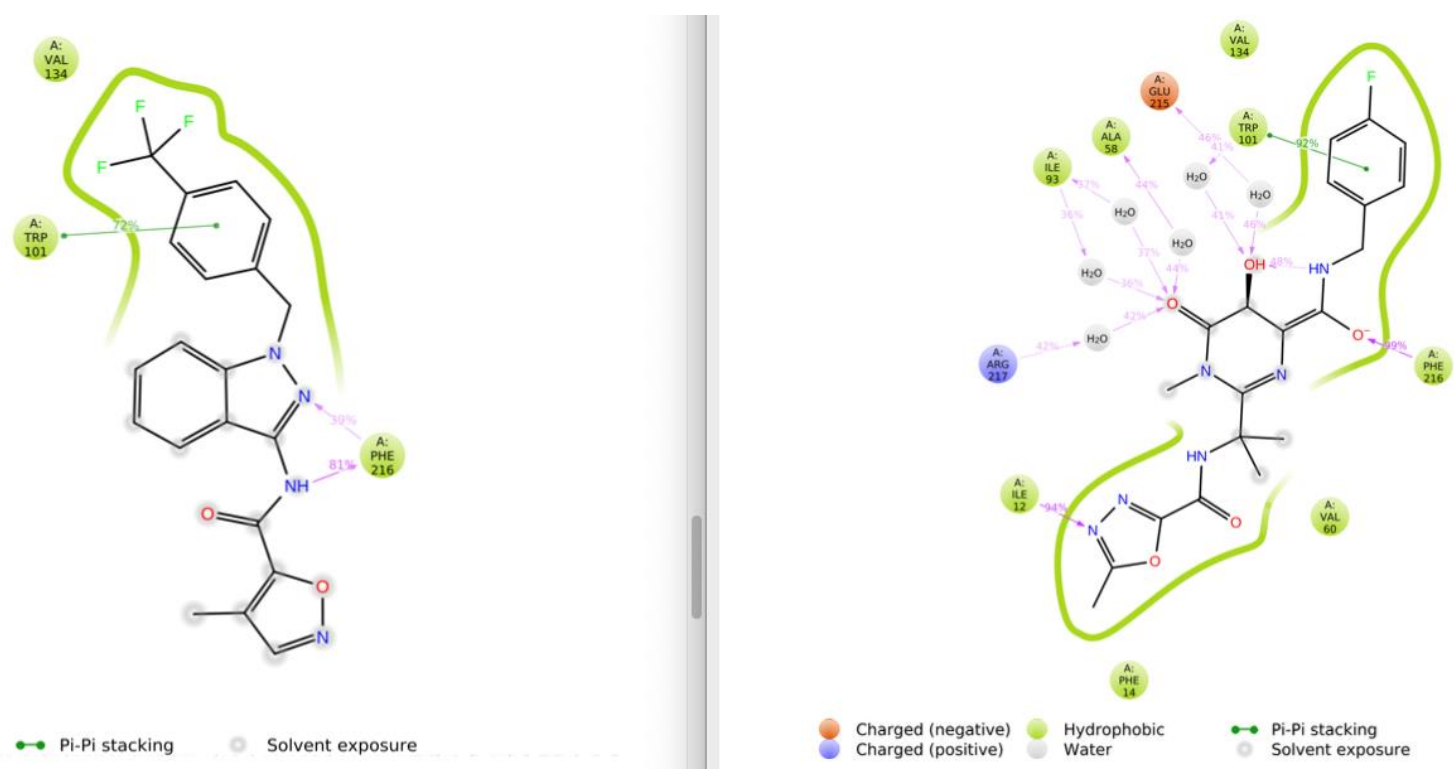

Figure 1. 2D representation of main protein-ligand interactions averaged over $100 \mathrm{~ns}$ between Fascin1 and NP-G2-029 (left) and raltegravir (RAL) (right).

\subsection{Differential Scanning Fluorimetry (Thermofluor) Study of Binding to Fascin1}

Binding of RAL to Fascin1 was investigated using Thermofluor (differential canning fluorimetry) assays, as described before [12]. The thermal unfolding profile of the protein, alone or in the presence of the putative ligand, was monitored following the fluorescence signal of Sypro Orange, a hydrophobic dye that increases its fluorescence signal upon binding to the hydrophobic patches that become exposed as the protein unfolds. Ligand binding increases the Tm of the unfolding transition in an amount proportional to the ligand-binding affinity.

As shown previously by Alburquerque-González et al. [12], at pH 7.4, Fascin1 unfolds in a single transition showing no concentration dependency and good tolerance to dimethyl sulfoxide (DMSO). RAL at a final concentration of $1 \mathrm{mM}$ in $10 \%$ DMSO was tested for binding to $2 \mu \mathrm{M}$ Fascin1, inducing a modest stabilization of the protein, which was indicative of a weak to moderate interaction with Fascin1. As shown in Figure 2, the binding of RAL to Fascin 1 was further validated in vitro using fluorescence titration experiments, which rendered a dissociation constant in the high microMolar range $(\mathrm{Kd}=180 \pm 10 \mu \mathrm{M})$. 
A

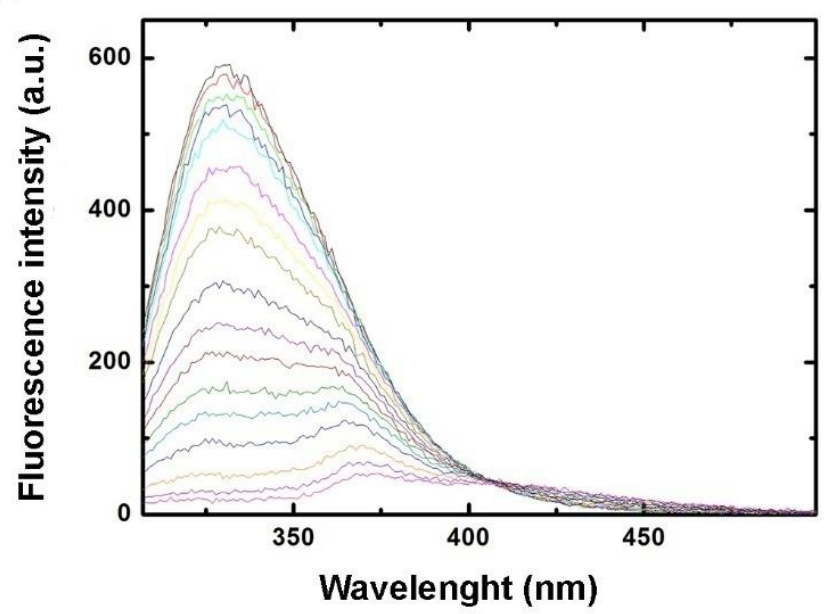

B

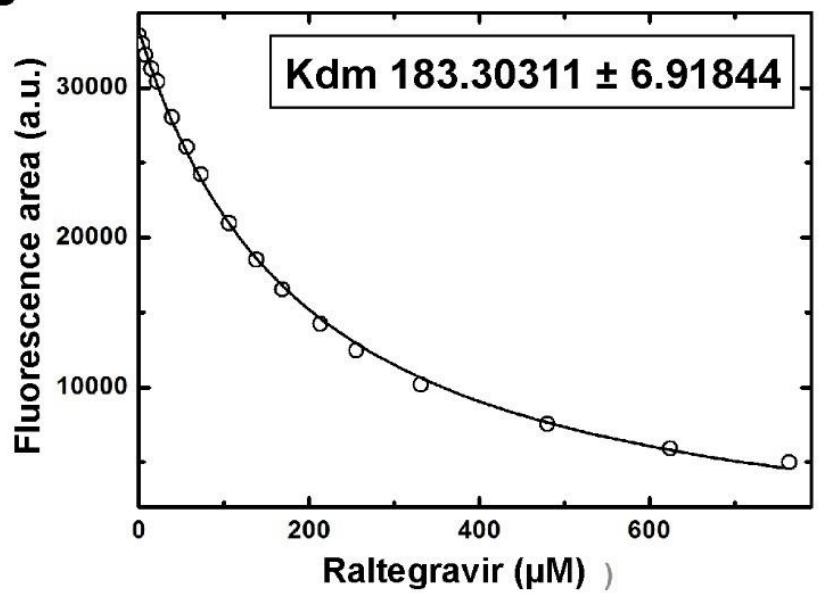

Figure 2. In vitro characterization of raltegravir binding to Fascin1. (A) Fluorescence titration experiment of Fascin1 with raltegravir. The fluorescence emission spectra of free Fascin1 are shown as a black line. Colored curves correspond to the emission spectra of Fascin 1 in the presence of increasing concentrations of raltegravir, ranging from $4 \mu \mathrm{M}$ (red) to $760 \mu \mathrm{M}$ (magenta). Binding of raltegravir induces a progressive decrease in emission intensity and a shift in the intensity maximum. (B) Binding isotherm of raltegravir to Fascin1, showing the area the emission peaks in panel A (white circles) as a function of raltegravir concentration. The continuous line corresponds to the best fit of the experimental data to a one-site binding thermodynamic model. 3.3. Ligand-observed NMR confirms RAL-Fascin1 interaction in vitro.

The interaction between RAL and recombinant Fascin1 was further confirmed by ligand-based NMR spectroscopy methods. Specifically, saturation transfer difference (STD) [17] and WaterLOGSY (WL) [18] NMR experiments were employed, which allow the direct assessment of the ligand-protein interaction in solution and are often used in high-throughput screenings thanks to their relatively fast acquisition time. Both experiments showed intensity changes in ligand resonances caused by nuclear Overhauser effect (NOE)-mediated magnetization transfer, as a consequence of the interaction with the target protein. In the STD experiment, two ${ }^{1} \mathrm{H}$ NMR spectra are recorded after on- or off-resonance protein-selective saturation pulse, respectively, and the difference spectrum is then calculated. Ligand-protein interaction is recognized by the presence of positive signals in the difference NMR spectrum, whereas the lack of interaction (e.g., in a control sample in the absence of protein) results in no signals. In the WL experiment, the large bulk water magnetization is partially transferred to the ligand in the protein-bound state, which then rapidly exchanges with the free ligand. A noninteracting compound results 
in positive resonances, whereas protein-ligand interactions are characterized by negative signals or by positive signals decreased in intensity with respect to the control sample. The above NMR experiments performed on RAL in the presence of Fascin 1 clearly show an interaction (Figure 3). Specifically, positive aromatic signals (see the inset in Figure 3a) were detected in the STD spectrum of the mixture, while being absent in the control spectrum (Figure 3b), and in the WL spectrum, the same signals decreased in intensity compared to the control (Figure 3c). As we can show into the Appendix A, similar effect was observed with the known Fascin1 inhibitors imipramine (Figure A2) and MGS (Figure A3), although the latter gave a less pronounced effect likely due to the absence of aromatic moieties, for which the experiments were optimized. Overall, the NMR data confirm that RAL directly interacts with Fascin1 in solution.
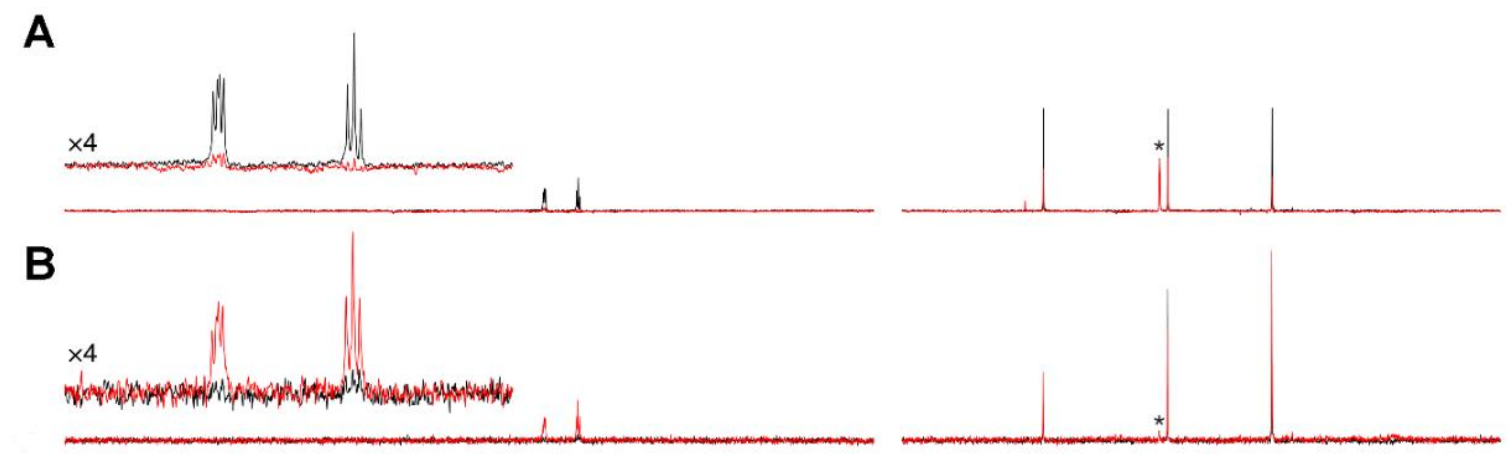

C

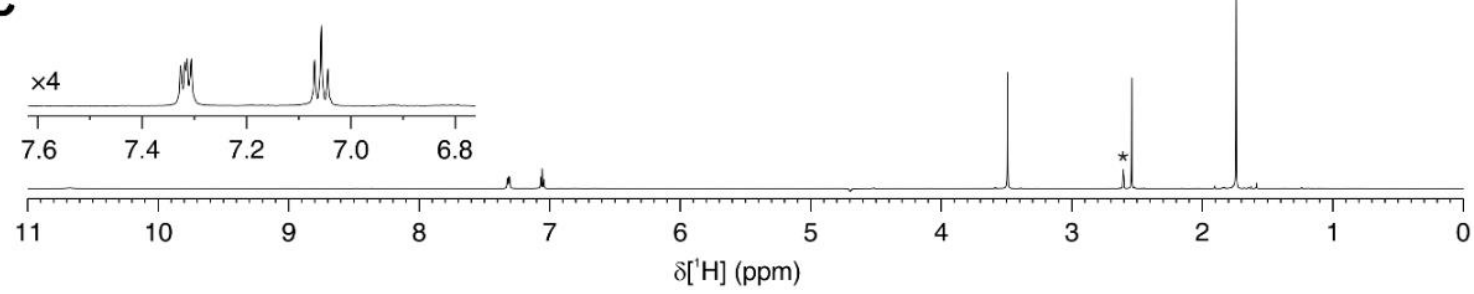

Figure 3. Interaction between raltegravir and Fascin1 observed by ligand-based NMR. (A) WaterLOGSY (WL) NMR spectra of $500 \mu \mathrm{M}$ raltegravir either alone (black) or in the presence of $10 \mu \mathrm{M}$ Fascin1 (red). The residual ${ }^{1} \mathrm{H}$ signal from d6-DMSO is marked with an asterisk. (B) Saturation transfer difference (STD) NMR spectra and (C) Reference ${ }^{1} \mathrm{H}$ NMR spectrum of raltegravir. The aromatic signals are shown in the insets on the left of each panel. The residual 1H signal from d6-DMSO is marked with an asterisk.

\subsection{RAL Prevents In Vitro Fascin1-Induced F-Actin Bundling}

In order to assess the effects of RAL on actin polymerization, we performed an Factin bundling assay, and the results were observed by transmission electronic microscopy (TEM). As shown in Figure 4, only F-actin incubated in the presence of untreated Fascin1 formed filament bundles. When Fascin1 was pre-incubated with either $100 \mu \mathrm{M} \mathrm{MGS,}$ $10 \mu \mathrm{M}$ imipramine, $10 \mu \mathrm{M}$ G2 compound, or $30 \mu \mathrm{M}$ RAL per separate, a disorganization of the bundles was observed, resulting in fewer filaments than in control conditions (KruskalWallis test, $p<0.001)$. Besides, RAL treatment produced significantly thinner filament bundles than MGS (Mann-Whitney test, $p<0.05$ ). 

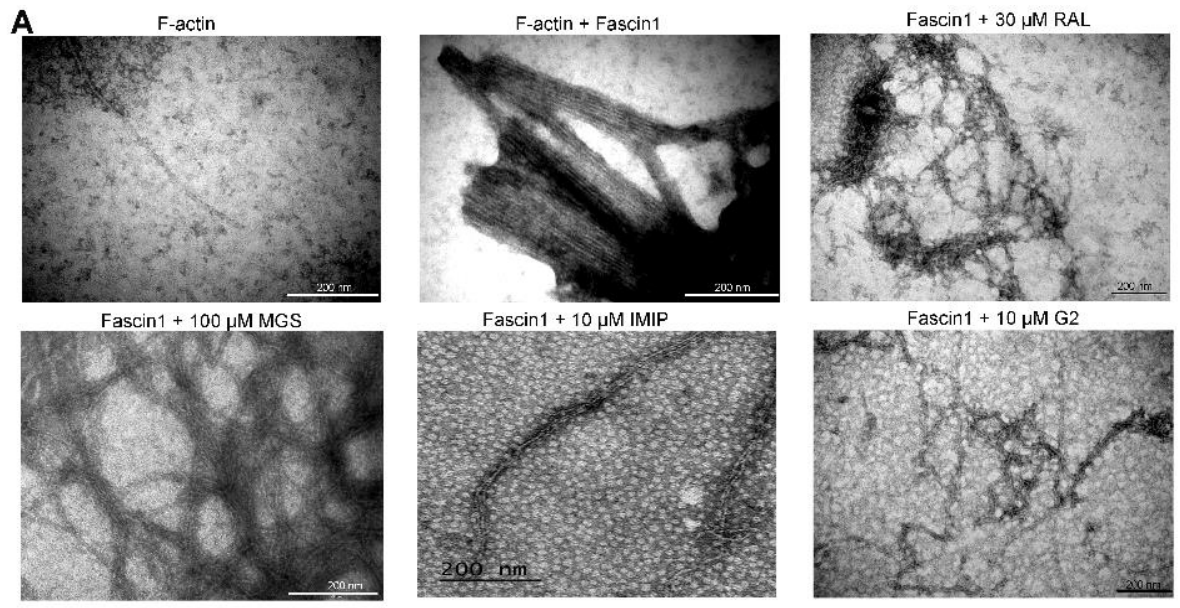

B

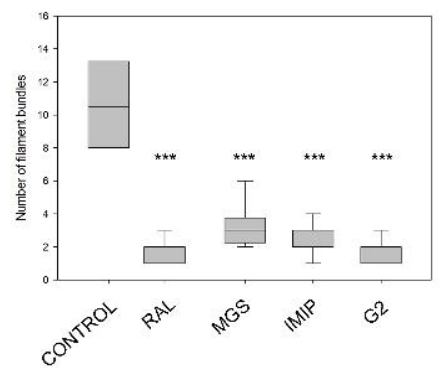

Figure 4. Fascin1 stimulation of actin-bundles formation is prevented by RAL. (A) Actin bundle formation in the presence of Fascin1 or Fascin1 with raltegravir (RAL) or different Fascin1-inhibitors: migrastatin (MGS), imipramine (IMIP) and, G2 compound; was visualized by transmission electronic microscopy (TEM). A representative figure is shown. (B) Quantitative analysis of the numbers of actin filaments of several pictures acquired by TEM $(* * * p<0.001)$.

\subsection{RAL Affects Actin Cytoskeleton Formation and Fascin1 Localization at Lamellipodia}

As previously reported by our group, HCT-116 and SW480 exhibited the highest Fascin1 expression, whilst LoVo, DLD-1, and HT-29 had the lowest amongst eight colorectal cancer cell lines [13]. In order to perform the in vitro studies with the highest and lowest endogenous Fascin1 expression, we selected DLD-1 (low Fascin1 expression) and HCT-116 (high Fascin1 expression) cell lines for subsequent assays.

To assess the effect of RAL on cell viability, we used DLD-1 and HCT-116 cell lines. RAL was well tolerated up to $30 \mu \mathrm{M}$, by the DLD-1 and HCT-116 cell lines (Appendix A, Figure A4). At the experiment, MGS was included as an internal control, confirming the tolerance to $100 \mu \mathrm{M}$ of both cell lines [13]. Then, the effect of RAL on lamellipodia protrusion at the cell front was assessed performing a wound scratch and observing Fascin1 localization by immunofluorescence of HCT- 116 cells. Because the DLD-1 cell line is not suitable for assessing actin-based protrusions [13], HaCaT cells were used instead which showed an intermediate Fascin1 expression between HCT-116 and DLD1 (as observed after consulting Proteinatlas and BioGps databases). In addition, we assessed the reorganization of the cytoskeleton by F-actin staining.

Because lamellipodia were linked to the migratory activity of the tumoral cells, we further tested whether RAL treatment was associated with cell lamellipodium number. Figure 5 shows that prominent lamellipodia formation were observed in control conditions and for epithelial growth factor (EGF) treated cells with significant differences between them. However, these cytoskeleton structures were absent in cells treated with RAL, similarly to what it was observed for both MGS and PD98059, a MEK1 and MEK2 inhibitor. Lamellipodia-protrusion numbers were significantly lowered upon RAL treatment, although MGS had a more powerful diminishing effect (Table 1). 

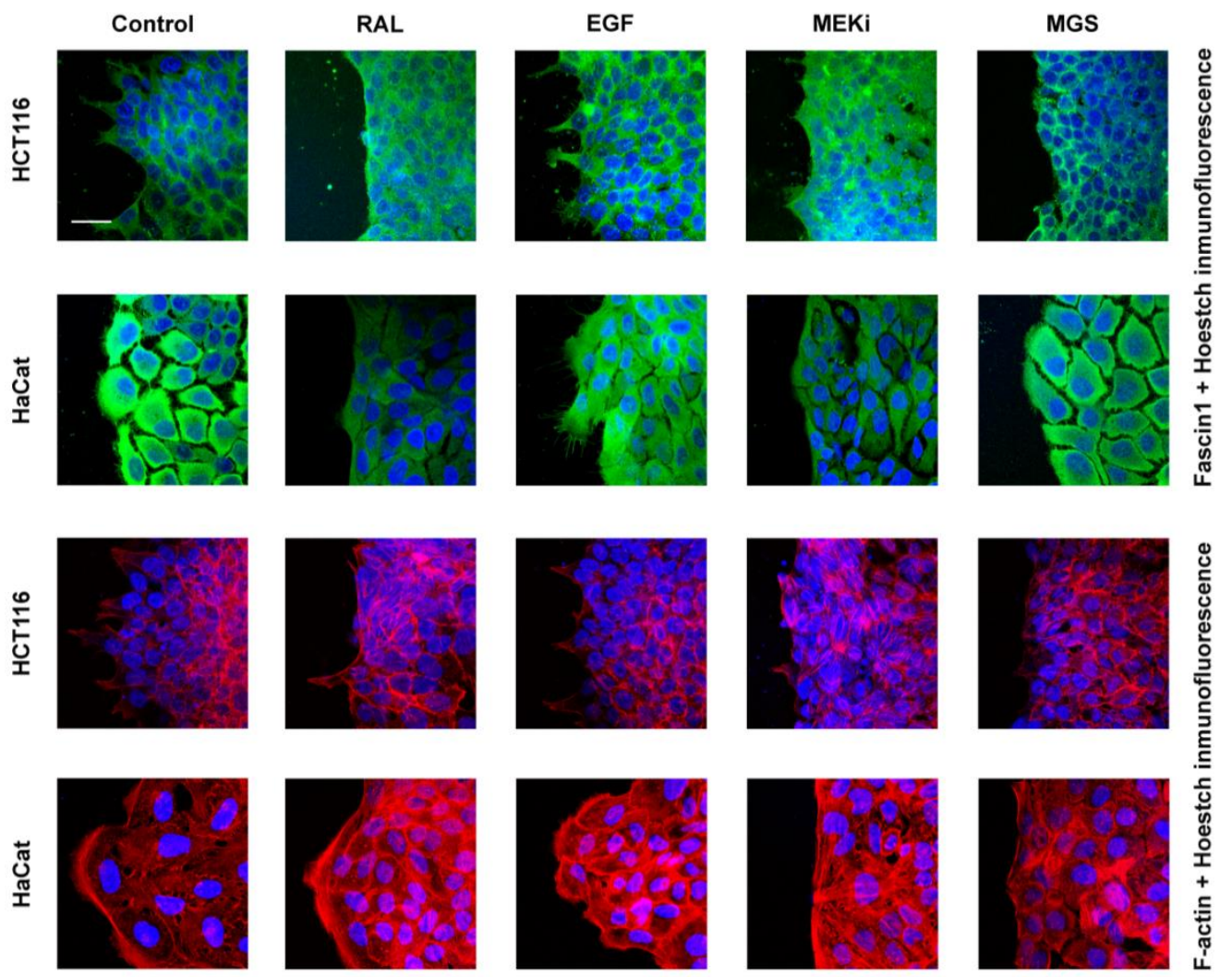

Figure 5. RAL inhibits the formation of lamellipodia and filopodia in HCT-116 and HaCaT cells, respectively. Confocal microscopy images of HCT-116 or HaCaT cells at the migrating edge on a wound scratch assay. Wounded cells were left untreated (control) or treated as indicated in the figure. Fascin1: green; Actin: red; Nuclei: blue; RAL: $30 \mu \mathrm{M}$ raltegravir; EGF: $10 \mathrm{ng} / \mathrm{mL}$ epithelial growth

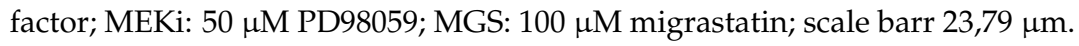

Table 1. Lamellipodium-protrusion numbers in the different conditions in HCT-116 cells.

\begin{tabular}{|c|c|c|c|c|c|}
\hline & Control & $30 \mu \mathrm{M}$ RAL & $10 \mathrm{ng} / \mathrm{mL}$ EGF & $50 \mu \mathrm{M}$ MEKi & $100 \mu \mathrm{M}$ MGS \\
\hline $\begin{array}{l}\text { Lamellipodium number } \\
\qquad p \text { value * }\end{array}$ & $8.7 \pm 1.73$ & $\begin{array}{c}6.73 \pm 1.11 \\
3.73 \times 10^{-5}\end{array}$ & $\begin{array}{c}11.58 \pm 2.35 \\
0.000026\end{array}$ & $\begin{array}{c}4.14 \pm 1.43 \\
5.76 \times 10^{-10}\end{array}$ & $\begin{array}{l}4.58 \pm 1.39 \\
3.14 \times 10^{-9}\end{array}$ \\
\hline
\end{tabular}

* T-test compared to control condition. Lamellipodium number was counted in pictures at $64 \times$.

\subsection{RAL Diminishes Migration and Inhibits Matrigel Cell Invasion of Colorectal Cancer Cells}

With the aim of verifying the properties of Fascin1 inhibitors on actin-based membrane protrusions involved in cell migration, an in vitro wound-healing scratch assay was carried out with cells treated with MGS and RAL. Figure 6 shows that RAL induces a considerable inhibition of HCT-116 DLD-1 cell migration when compared to control conditions $(p<0.05)$.

Tumor cell invasion comprises both the gain of migration capabilities and the faculty to degrade extracellular matrix components such as basement membrane and tumor stoma [23]. Consequently, we carried out a Transwell assay on Matrige ${ }^{\mathrm{R}}$ because it resembles the composition of basement membrane and extracellular matrix. To further verify the inhibitory role of RAL on Fascin 1 activity, we used Fascin1 overexpressed DLD-1 cells and tested their invasion properties. Accordingly, $30 \mu \mathrm{M}$ RAL strongly diminished migration and invasion in Fascin1 overexpressed DLD-1 cells $(p<0.01)$ (Appendix A Figure A5A). As shown in Appendix A Figure A5B, RAL inhibit tumor-cell invasion of HCT-116, such as another tested inhibitor, G2 compound. 
A

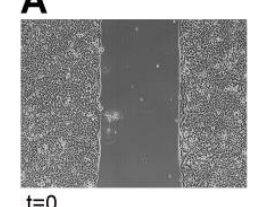

$t=0$

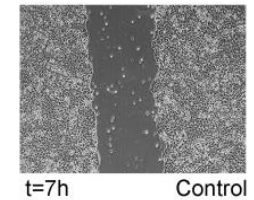

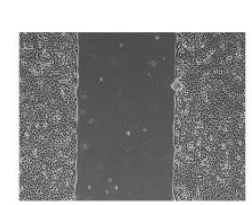

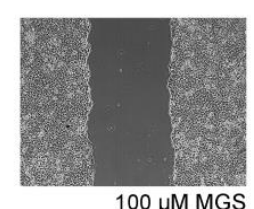

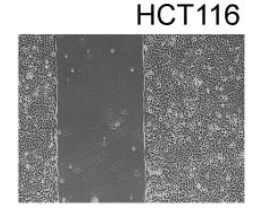

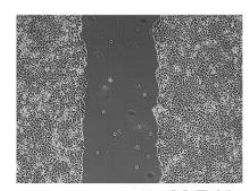

$30 \mu \mathrm{M}$ RAL
B
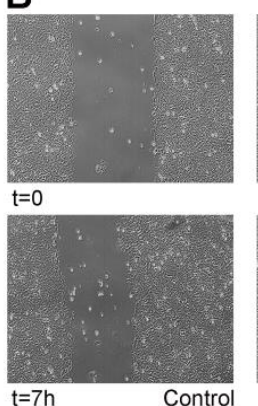

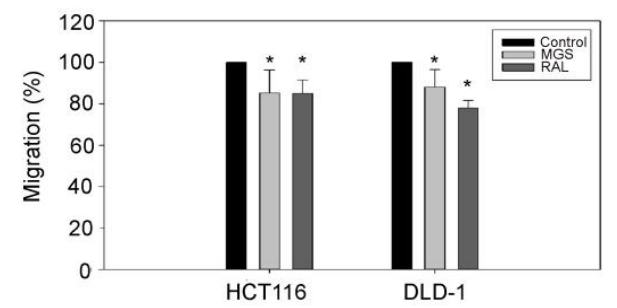

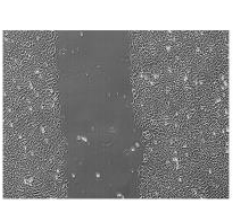

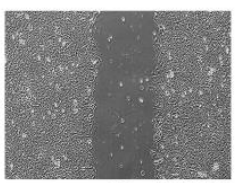

$100 \mu \mathrm{M}$ MGS
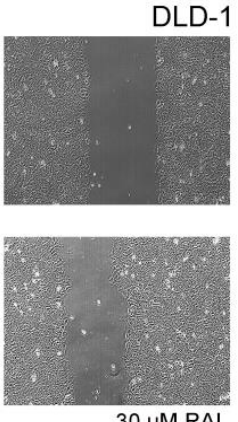

C

Figure 6. Inhibition of two cell lines by migrastatin (MGS) and RAL. (A) HCT-116, (B) DLD-1, (C) Migration was calculated with respect to the control conditions in lineal phase $\left({ }^{*} p<0.05\right)$.

\subsection{RAL Inhibits the Invasive and Metastatic Capacity of Colorectal Tumor Cells in an In Vivo Model}

Cancer cell lines in tissue culture are widely utilized in early-stage evaluation of potential cancer targets however, the use of animal models is also crucial. In order to extrapolate the above anti-invasive properties to in vivo experiments, the well-established zebrafish larvae model of invasion as well as a xenograft assay was carried out (Figure 7). Most larvae were viable upon treatment with different RAL concentrations (Appendix A, Figure A6). A correlation between invasion percentage and Fascin1 mRNA expression was observed, where HCT-116 cells showed the highest and LoVo and DLD-1 the lowest expression of Fascin1 as previously reported [12]. Therefore, HCT-116 was chosen as the cell line with the highest constitutive expression of Fascin1, whereas DLD1 transfected with Fascin1 was considered as the condition of induced Fascin1 expression. The transfection efficiency was proven previously. The Fascin1-transfected cells increased the protein expression level more than $20 \%$ compared to the control condition [12]. The Fascin1transfected cells increased the protein expression level and the percentage of the zebrafish larvae invasion (Figure 7C,D). HCT-116 tumor cells injected in larvae treated with RAL exhibited a significantly lower percentage of invasion and lower number of invasion foci than control and similarly to that observed for MGS treatment (Figure 7A,B). Likewise, when Fascin1-transfected DLD-1 cells were injected, RAL and MGS inhibitory effect was increased compared to untreated conditions, thus suggesting a Fascin1-dependent activity of these drugs. The reduction in the percentage of invasion compared to control (DMSO) was higher when DLD-1 cells were transfected with Fascin1 than when DLD-1 cell were transfected with the empty vector for both treatments.

When larvae were fed and kept alive after six days post-xenograft, micro-metastasis developed from invading tumor cells (Figure 8B). As shown in Figure 8A, HCT-116 colorectal cancer cells treated with $30 \mu \mathrm{M}$ RAL diminished the total number of larvae in which metastasis was observed. DLD-1 cells transfected with Fascin1-GFP plasmid showed a significant increase in metastatic larvae compared to pGFP-N3 control vector (MOCK). The reduction in the percentage of metastasis compared to control (DMSO) was higher when DLD-1 cells were transfected with Fascin1 (64.5\%) than when DLD-1 cell were transfected with the empty vector $(22.9 \%)$ This metastatic activity diminished when larvae was treated with RAL. All these findings suggest a Fascin1-dependent effect of RAL. 


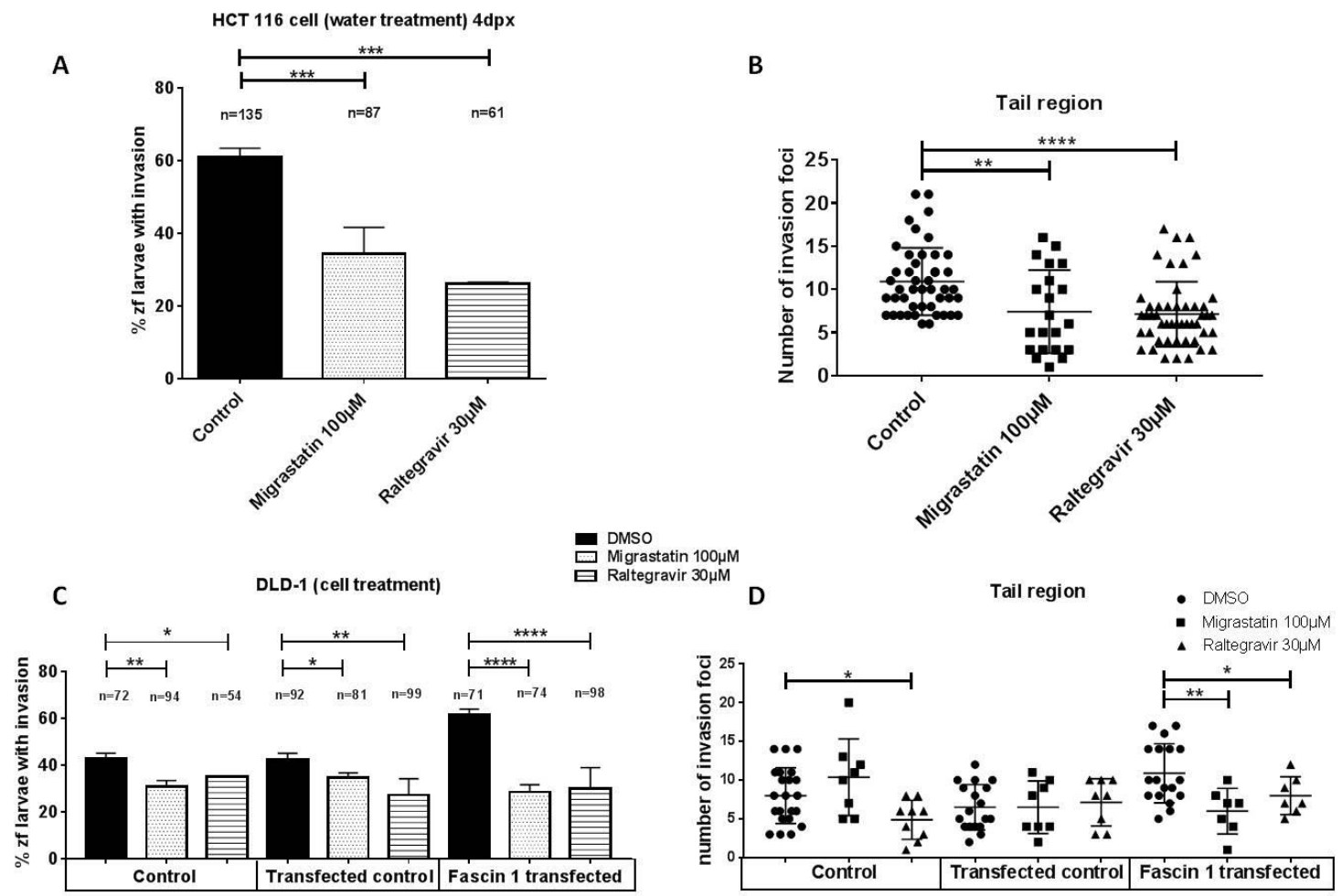

Figure 7. Zebrafish invasion assays 4 days post-xenograft. (A) The images show the invasive and non-invasive cells in a zebrafish invasion model. On the right panel, the invasiveness of each cell line is shown. (B) HCT-116 cancer cells were injected in zebrafish larvae and then treated with migrastatin and RAL. (C) Effects of drugs on the average percentage of zebrafish larvae with invasion in Fascin1-transfected DLD-1 cells. (D) Effects of drugs on the number of invasion foci in Fascin1-transfected DLD-1 cells. Data are shown as mean \pm SD; compared with the control condition, ${ }^{*} p=0.049-0.01$. ${ }^{* *} p=0.001-0.009$. ${ }^{* * *} p=0.0001-0.0009$. ${ }^{* * * *} p<0.0001$.

A
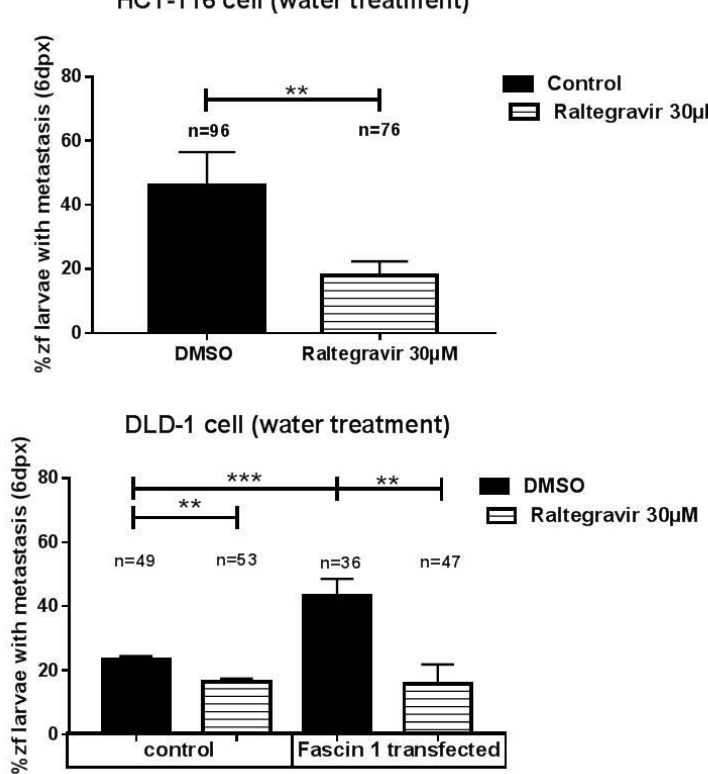

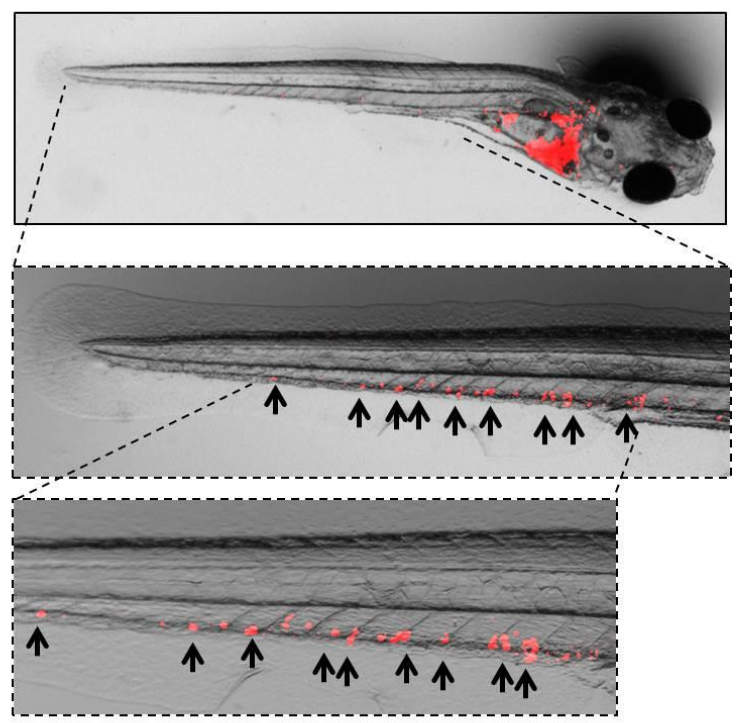

Figure 8. Anti-metastatic potential of RAL in zebrafish. (A) At six days post-injection, larvae were examined to evaluate whether micro-metastasis developed by invading native HCT-116 and Fascin1-transfected DLD-1 cells. (B) The evaluation criteria were the presence of human cancer-cell colonies (arrows) outside the yolk sac. Data are shown as mean $\pm \mathrm{SD}$; compared with the control condition, ${ }^{* *} p=0.001-0.009$. ${ }^{* * *} p=0.0001-0.0009$. 


\section{Discussion}

There is a considerable lapse of time between the discovery of novel potential targets involved in cancer and the development of a successful therapy. The strategy of using existing drugs originally developed for one disease to treat other indications has found success across medical fields. This approach is known as drug repurposing, and it promises faster access of drugs to patients while reducing costs in the long and difficult process of drug development [24]. By using VS for inhibiting pro-invasive and pro-metastatic Fascin1 protein, we identified the VIH antiretroviral, RAL, as a potential drug for treating Fascin1 overexpressing cancers.

The use of antiretrovirals as cancer treatments is not new. Apart from obvious anti-VIH anti-neoplastic effects reported in virus-associated tumors such as Kaposi's sarcoma [25] and Xenotropic murine leukemia-related retrovirus, which has been linked to human prostate cancer and chronic fatigue syndrome [26], several evidences highlight the antitumoral properties of anti-retrovirals including RAL. The findings reported in our study do not rule out that RAL could bind other proteins with actin-binding action. In this regard, RAL was found to inhibit $\gamma$-actin binding protein, Aldolase A in a xenograft model of lung cancer with no significant toxicity [27]. In fact, by using Pocketalign and the PDB structural information for Aldolase A and Fascin1, it was found that both proteins share a common hydrophobic pocket at the actin-binding site.

Another group of evidence points out the effect of anti-retrovirals in restoring the sensitivity to chemotherapeutic agents. In this line, zidovudine back in 1989 was found to increase sensitivity to cisplatin in resistant human colon cells in vitro [28]. Also, a pilot, serial biopsy study is ongoing in which the potentiation of cisplatin chemotherapy by RAL is being evaluated in patients with head and neck squamous cell carcinoma [29]. Interestingly, another effect of Fascin1, apart from actin cytoskeleton rearrangement, is conferring chemoresistance to tumor cells [30,31]. Cancer drug resistance remains a burden for cancer therapy and patients' outcome, and it often results in more aggressive tumors that tend to metastasize to distant organs. It might be thus envisaged that Fascin 1 could represent a novel target to overcome resistance, and our results warrant further research with chemoresistant tumoral cells and RAL.

In addition, actin-bundling activity of Fascin 1 has been proven to facilitate release and cell-to-cell transmission of human T-cell leukemia virus type 1 (HTLV1) retrovirus [32] and, more recently, pseudorabies virus (PRV) [33]. Likewise, Epstein-Barr virus (EBV)encoded oncoprotein (lmp1) via NF-kappaB in lymphocytes induces Fascin1 to increase their invasiveness [34]. In fact, human Fascin1 was firstly cloned and sequenced as a protein over 200-fold induced, by latent Epstein-Barr virus (EBV) infection in B lymphocytes and was absent in non-EBV-infected B- and T-cell lines [35]. Moreover, Fascin1 immuno-histochemical expression was significantly related with EBV-associated gastric and colorectal carcinomas [36,37] and HIV-related lymphoid hyperplasia [38]. Most of these viruses express short miRNAs to regulate their own gene expression or to influence host gene expression and thus contribute to the carcinogenic processes. Fascin 1 has been also shown regulated by miRNA-200b, miRNA-539, miRNA-133b, and miRNA-145 [39-42], and thus, a targeted link between viral infection and Fascin1 could also be envisaged. However, the therapeutic effects of antiviral drugs on tumors which overexpress Fascin1 have not been investigated yet.

The aim of this study was to characterize the anti-Fascin1, antimigratory and antiinvasive properties of the anti-retroviral drug, RAL, by using molecular modeling, biophysical and biochemical techniques, immunofluorescence, migration, and invasion assays. In addition, the in vivo effect of RAL was evaluated in metastatic zebrafish model. This study also emphasizes the exciting approaches to decipher novel drugs, sometimes FDAapproved, and their mechanisms of action. Apart from disrupting the role of Fascin1 in tumor-cell invasion and metastasis via inhibiting actin-based membrane protrusions, RAL could also abrogate cancer metastatic colonization by blocking metabolic stress resistance and mitochondrial oxidative phosphorylation (OXPHOS), as Fascin1 has shown to be 
involved also in stabilizing mitochondrial actin filaments under metabolic stress, at least in lung cancer [43]. Hence, this is the first description on the in vitro and in vivo antitumoral activity of RAL on colorectal cancer cells, which has been previously predicted by VS calculations, thus guiding the design of improved Fascin1 inhibitors. Our results could contribute to the repurposing of this HIV-1 integrase inhibitor for the treatment of Fascin1-overexpressing tumors.

\section{Conclusions}

By using VS calculations, we identified, for the first time, RAL as a potential Fascin1 blocker, subsequently being shown by biophysical assays, and also as an inhibitor of cell migration and invasion of human colorectal cancer cells. We also demonstrated the feasibility of docking, molecular-dynamics simulations, and NMR to provide details about the main potential interactions between RAL and Fascin1 key residues and further targeting this mechanism in vitro. Our results also suggest that RAL is likely to reduce the in vivo antimigratory and anti-invasive activity using a zebrafish model with xenograft tumor implants. Importantly, the potential FDA-approved compound used in the present study, which is classified as safe in humans, could be easily repurposed as novel antitumoral drug and used in proof-of-concept clinical trials. Further in vivo studies to evaluate this novel Fascin1-targeted approach are warranted.

\section{Patents}

Conesa-Zamora P, Alburquerque-González B, Pérez-Sánchez H, Montoro-García S, García-Solano J, Bernabé-García A, Nicolás-Villaescusa FJ, Bernabé-García M, CayuelaFuentes ML, Peña-García J, Luque-Fernández I, Ruiz-Sanz J, and Martínez-Herrerías JC. Patent pending no. P202130062.

Author Contributions: P.C.-Z., S.M-G. and H.P.-S. conceived the presented idea. P.C.-Z., S.M.-G., F.J.N., M.L.C.-F. and H.P.-S. designed the experiments and supervised the findings of this work. B.A.-G., H.P.-S., Á.B.-G., S.M.-G., L.G., L.B., M.B.-G., F.F.L.-C., J.P.-G. and J.R.-S. performed the experiments. P.C.-Z., B.A.-G., S.M.-G., H.P.-S., I.L. and E.L. wrote the manuscript. All authors have read and agreed to the published version of the manuscript.

Funding: This research was funded by Instituto de Salud Carlos III (Spanish Ministry of Health) and FEDER funds (references: PI15/00626 and PI18/00144), European Commission's Corbel Program (PID-3630, and 2334 and 2428); Spanish Ministry of Economy and Competitiveness MINECO (CTQ2017-87974-R), and by the Fundación Séneca del Centro de Coordinación de la Investigación de la Región de Murcia (20988/PI/18 and 20646/JLI/18). B.A.-G. belongs to the "Programa de Doctorado en Ciencias de la Salud, Universidad Católica de Murcia (UCAM)" and holds a grant of the UCAM (FPI05-UCAM/17). F.F.L.-C. was supported by the Junta Provincial Murcia Predoctoral Asociación Española contra el Cáncer (AECC) (REF: PRDMU19002) grant.

Institutional Review Board Statement: The study was conducted according to the guidelines of the Declaration of Helsinki, and approved by the Animal Welfare Ethics Committee of Instituto Murciano de Investigaciones Biosanitarias (IMIB)(REGA code: ES-300303340098).

Informed Consent Statement: Not applicable.

Data Availability Statement: No new data were created or analyzed in this study apart from those presented in the manuscript. Data sharing is not applicable to this article.

Acknowledgments: Supercomputing resources in this work have been supported by the infrastructures of Poznan Supercomputing Center, the e-infrastructure program of the Research Council of Norway, and the supercomputer center of UiT-the Arctic University of Norway, by the Plataforma Andaluza de Bioinformática of the University of Málaga, by the supercomputing infrastructure of the NLHPC (ECM-02, Powered@NLHPC), and by the Extremadura Research Centre for Advanced Technologies (CETA-CIEMAT), funded by the European Regional Development Fund (ERDF). CETA-CIEMAT belongs to CIEMAT and the Government of Spain.

Conflicts of Interest: The authors declare no conflict of interest. 


\section{Appendix A}

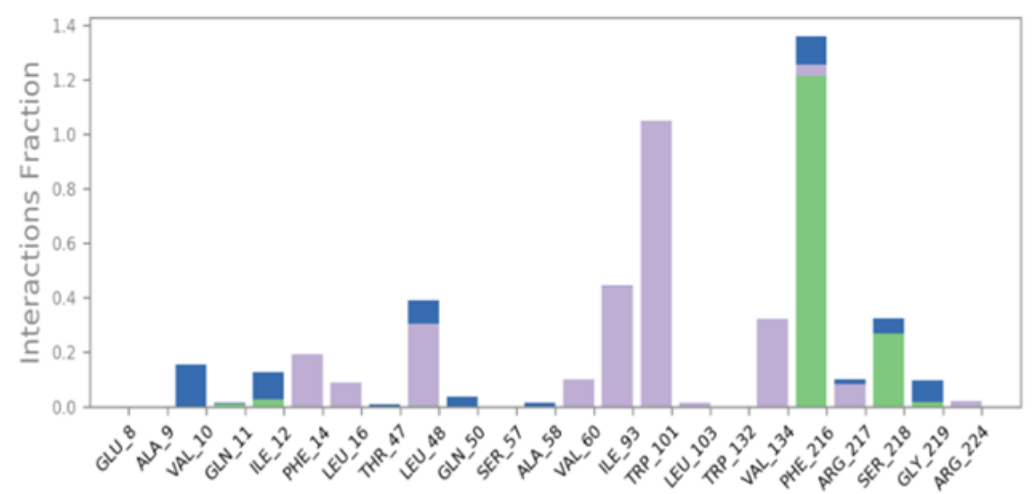

(a)

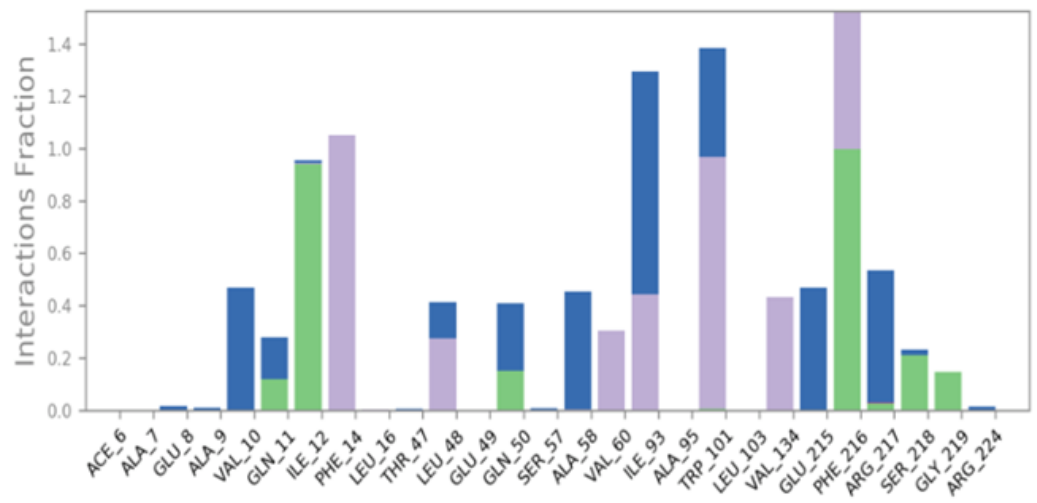

(b)

H-bonds $\square$ Hydrophobic $\square$ lonic $\square$ Water bridges

Figure A1. Top interacting residues and interaction types between Fascin1-6b0t_lig (a) and Fascin1RAL (b).

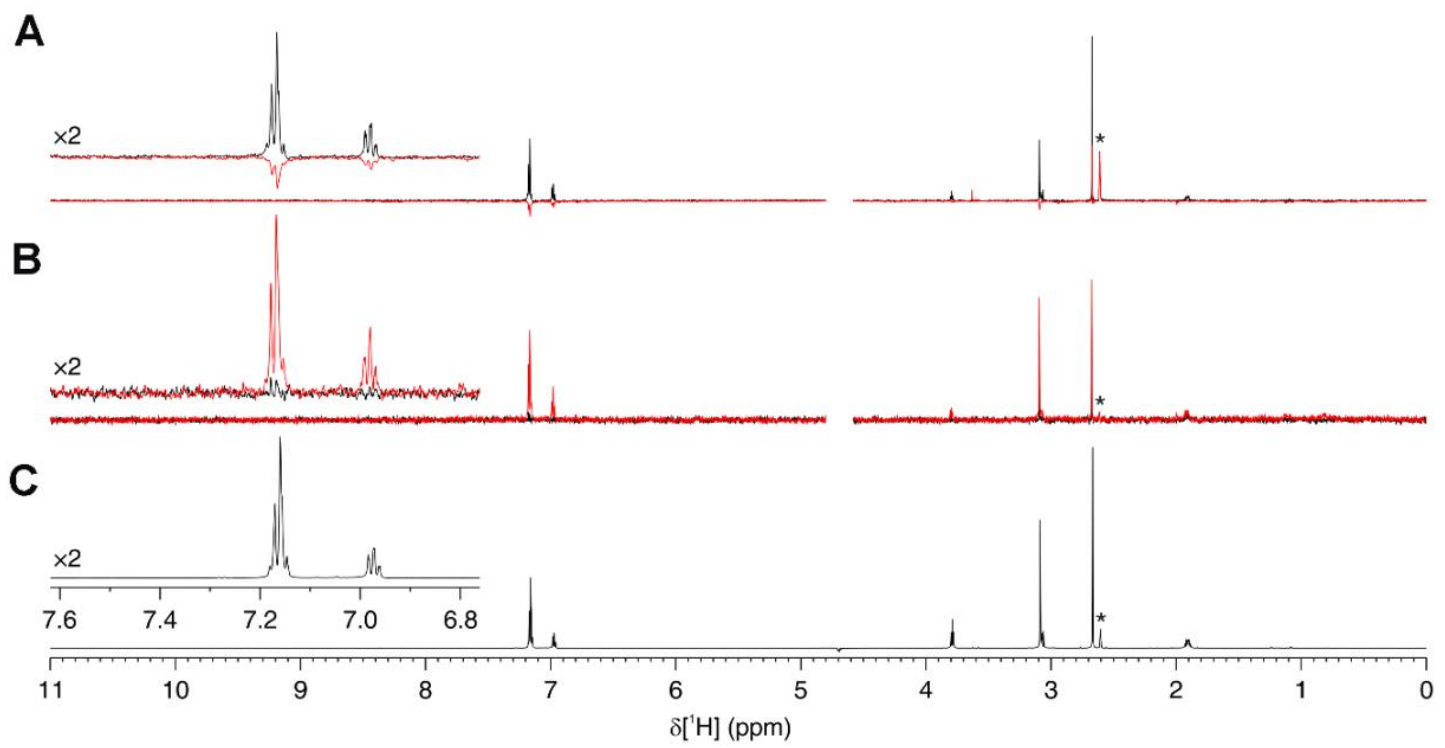

Figure A2. Interaction between imipramine and Fascin1 was observed by ligand-based NMR. (A) WL NMR spectra of $500 \mu \mathrm{M}$ imipramine either alone (black) or in the presence of $10 \mu \mathrm{M}$ Fascin1 (red); (B) STD NMR spectra and (C) reference ${ }^{1} \mathrm{H}$ NMR spectrum of imipramine. The residual ${ }^{1} \mathrm{H}$ signal from d6-DMSO is marked with an asterisk. The aromatic signals are shown in the insets on the left of each panel. The residual 1H signal from d6-DMSO is marked with an asterisk. 


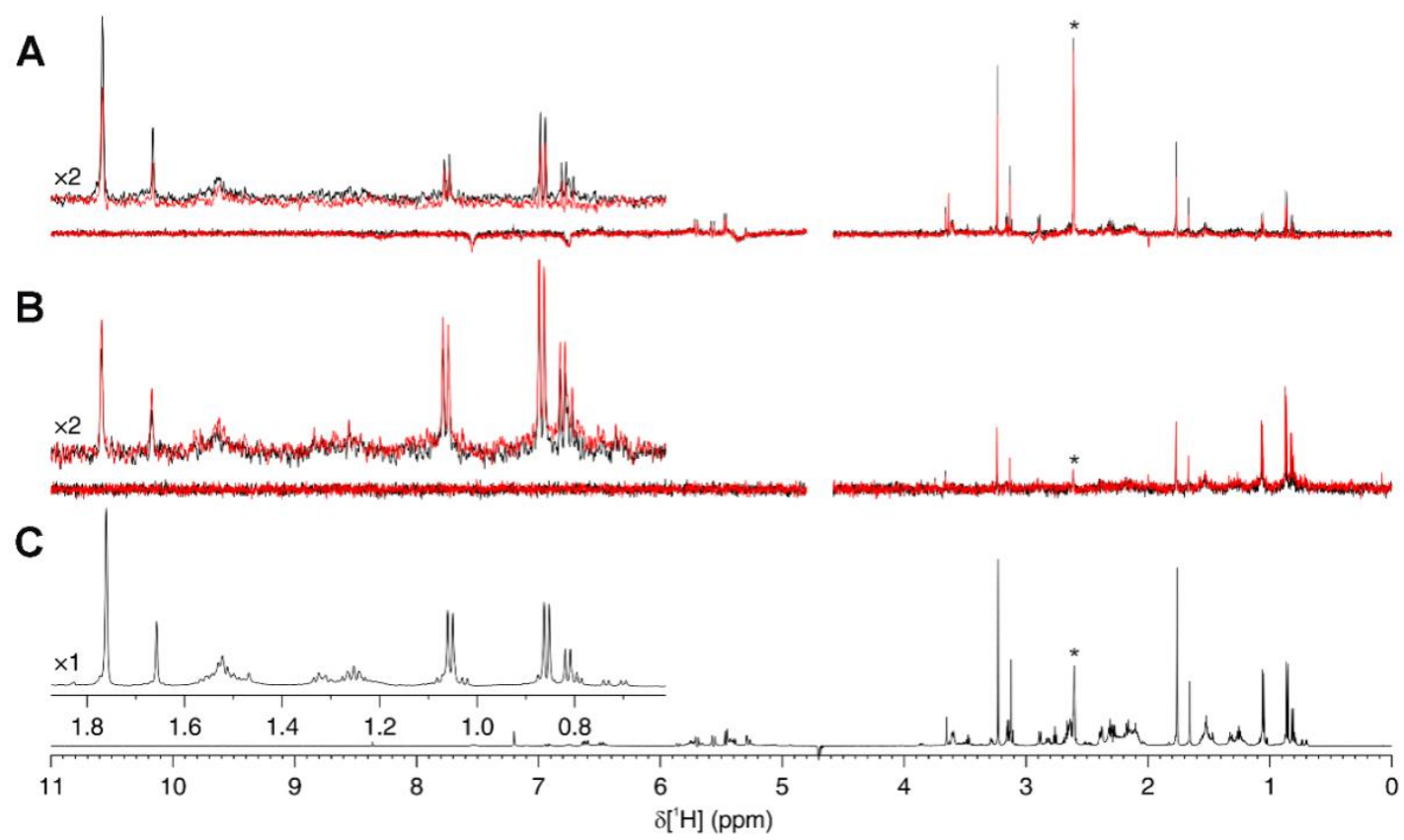

Figure A3. Interaction between migrastatin and Fascin1 was observed by ligand-based NMR. (A) WL NMR spectra of $500 \mu \mathrm{M}$ migrastatin either alone (black) or in the presence of $10 \mu \mathrm{M}$ Fascin1 (red); (B) STD NMR spectra and (C) reference ${ }^{1} \mathrm{H}$ NMR spectrum of migrastatin. The residual ${ }^{1} \mathrm{H}$ signal from d6-DMSO is marked with an asterisk. The aliphatic signals most affected from the interaction are shown in the insets on the left of each panel. The residual 1H signal from d6-DMSO is marked with an asterisk.

A

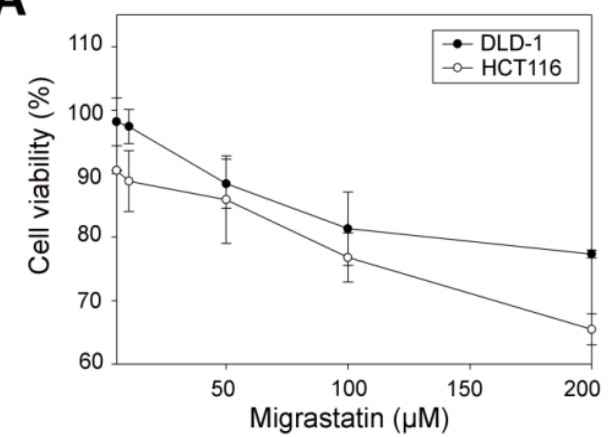

B

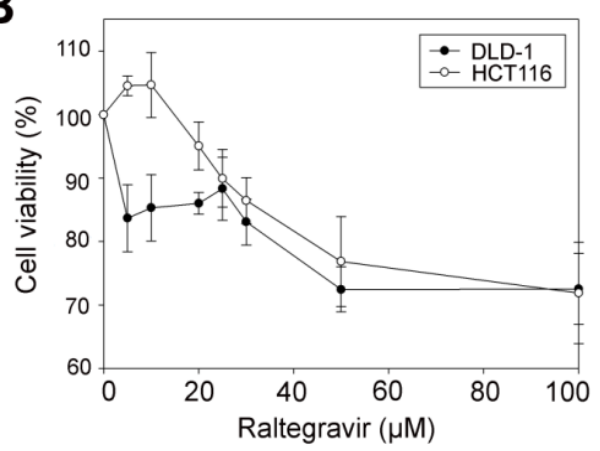

Figure A4. Shows the colorectal cell-line viability assay. The effect of anti-Fascin1 migrastatin (A); and RAL (B) on the cell viability of DLD-1 and HCT-116 colorectal cell lines is shown. 
A
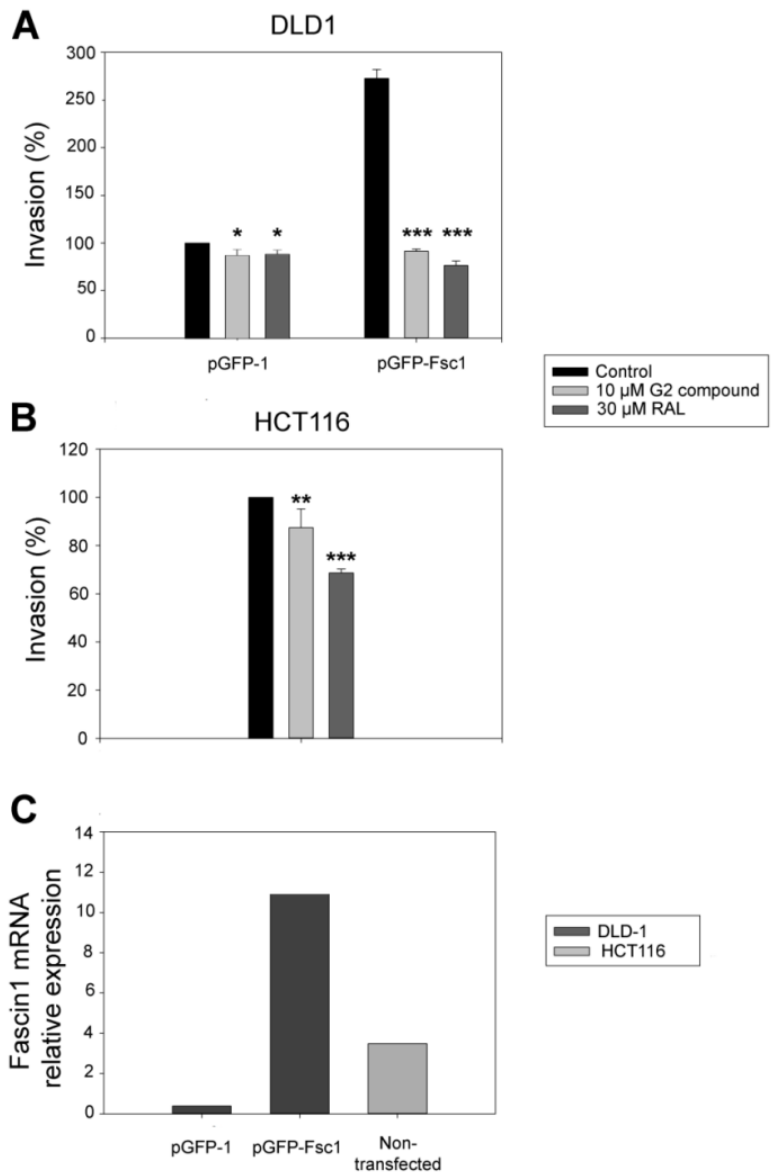

Figure A5. RAL (RAL) and G2 compound inhibition of the cell's invasive ability. (A) Percentage of invasion in DLD-1 Fascin1-transfected cells (pGFP vs pGFP-FSC1). (B) Percentage of invasion in HCT-116 non-transfected cells. (C) Fascin1 mRNA levels expressed in transfected DLD-1 cells. ${ }^{*} p=0.049-0.01 .{ }^{* *} p=0.001-0.009 .{ }^{* * *} p=0.0001-0.0009$.

A

Treatment of larvae in E3 medium

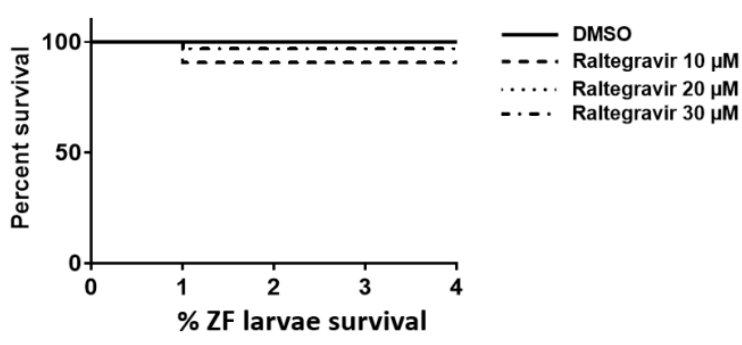

B

C

DLD-1 transfected cells

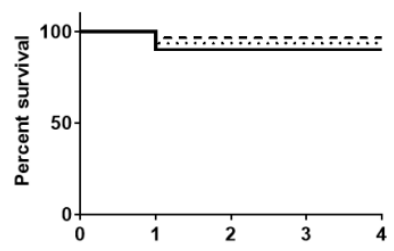

HCT 116 cells

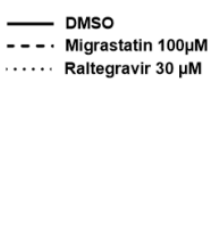

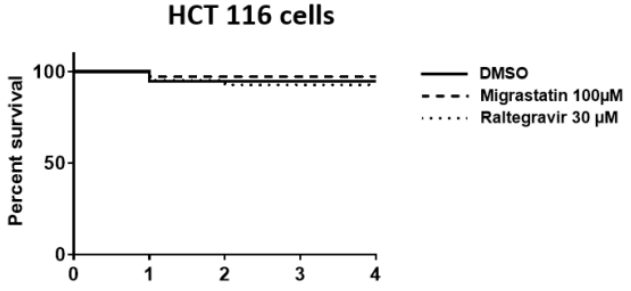

Figure A6. Survival curves of zebrafish larvae when treated with the raltegravir and migrastatin in the E3 medium (A) and when additionally, they were injected with (B) Fascin1-transfected DLD-1 or (C) HCT-116 tumor cell lines. 


\section{References}

1. Bray, F.; Ferlay, J.; Soerjomataram, I.; Siegel, R.L.; Torre, L.A.; Jemal, A. Global cancer statistics 2018: GLOBOCAN estimates of incidence and mortality worldwide for 36 cancers in 185 countries. CA Cancer J. Clin. 2018, 68, 394-424. [CrossRef]

2. Conesa-Zamora, P.; García-Solano, J.; Turpin, M.e.C.; Sebastián-León, P.; Torres-Moreno, D.; Estrada, E.; Tuomisto, A.; Wilce, J.; Mäkinen, M.J.; Pérez-Guillermo, M.; et al. Methylome profiling reveals functions and genes which are differentially methylated in serrated compared to conventional colorectal carcinoma. Clin. Epigenet. 2015, 7, 101. [CrossRef]

3. García-Solano, J.; Conesa-Zamora, P.; Carbonell, P.; Trujillo-Santos, J.; Torres-Moreno, D.; Pagán-Gómez, I.; Rodríguez-Braun, E.; Pérez-Guillermo, M. Colorectal serrated adenocarcinoma shows a different profile of oncogene mutations, MSI status and DNA repair protein expression compared to conventional and sporadic MSI-H carcinomas. Int. J. Cancer 2012, 131, 1790-1799. [CrossRef]

4. Stefanius, K.; Ylitalo, L.; Tuomisto, A.; Kuivila, R.; Kantola, T.; Sirniö, P.; Karttunen, T.J.; Mäkinen, M.J. Frequent mutations of KRAS in addition to BRAF in colorectal serrated adenocarcinoma. Histopathology 2011, 58, 679-692. [CrossRef]

5. Alburquerque-González, B.; López-Calderón, F.F.; López-Abellán, M.D.; Esteban-Gil, Á.; García-Solano, J.; Conesa-Zamora, P. Biology and Therapeutic Targets of Colorectal Serrated Adenocarcinoma; Clues for a Histologically Based Treatment against an Aggressive Tumor. Int. J. Mol. Sci. 2020, 21, 1991. [CrossRef] [PubMed]

6. Tan, V.Y.; Lewis, S.J.; Adams, J.C.; Martin, R.M. Association of fascin-1 with mortality, disease progression and metastasis in carcinomas: A systematic review and meta-analysis. BMC Med. 2013, 11, 52. [CrossRef]

7. Rodrigues, P.C.; Sawazaki-Calone, I.; de Oliveira, C.E.; Soares Macedo, C.C.; Dourado, M.R.; Cervigne, N.K.; Miguel, M.C.; Ferreira do Carmo, A.; Lambert, D.W.; Graner, E.; et al. Fascin promotes migration and invasion and is a prognostic marker for oral squamous cell carcinoma. Oncotarget 2017, 8, 74736-74754. [CrossRef] [PubMed]

8. Scott, K.L.; Nogueira, C.; Heffernan, T.P.; van Doorn, R.; Dhakal, S.; Hanna, J.A.; Min, C.; Jaskelioff, M.; Xiao, Y.; Wu, C.J.; et al. Proinvasion metastasis drivers in early-stage melanoma are oncogenes. Cancer Cell 2011, 20, 92-103. [CrossRef]

9. Lin, S.; Taylor, M.D.; Singh, P.K.; Yang, S. How does fascin promote cancer metastasis? FEBS J. 2020. [CrossRef] [PubMed]

10. Guo, S.; Zou, J.; Wang, G. Advances in the proteomic discovery of novel therapeutic targets in cancer. Drug Des. Dev. 2013, 7 , 1259-1271. [CrossRef] [PubMed]

11. Conesa-Zamora, P.; García-Solano, J.; García-García, F.; Turpin, M.e.C.; Trujillo-Santos, J.; Torres-Moreno, D.; Oviedo-Ramírez, I.; Carbonell-Muñoz, R.; Muñoz-Delgado, E.; Rodriguez-Braun, E.; et al. Expression profiling shows differential molecular pathways and provides potential new diagnostic biomarkers for colorectal serrated adenocarcinoma. Int. J. Cancer 2013, 132, $297-307$. [CrossRef] [PubMed]

12. Alburquerque-González, B.; Bernabé-García, M.; Montoro-García, S.; Bernabé-García, Á.; Rodrigues, P.C.; Ruiz Sanz, J.; LópezCalderón, F.F.; Luque, I.; Nicolas, F.J.; Cayuela, M.L.; et al. New role of the antidepressant imipramine as a Fascin1 inhibitor in colorectal cancer cells. Exp. Mol. Med. 2020, 52, 281-292. [CrossRef] [PubMed]

13. Montoro-García, S.; Alburquerque-González, B.; Bernabé-García, Á.; Bernabé-García, M.; Rodrigues, P.C.; den-Haan, H.; Luque, I.; Nicolás, F.J.; Pérez-Sánchez, H.; Cayuela, M.L.; et al. Novel anti-invasive properties of a Fascin1 inhibitor on colorectal cancer cells. J. Mol. Med. 2020, 98, 383-394. [CrossRef]

14. Chen, L.; Yang, S.; Jakoncic, J.; Zhang, J.J.; Huang, X.Y. Migrastatin analogues target fascin to block tumour metastasis. Nature 2010, 464, 1062-1066. [CrossRef] [PubMed]

15. Trott, O.; Olson, A.J. AutoDock Vina: Improving the speed and accuracy of docking with a new scoring function, efficient optimization, and multithreading. J. Comput. Chem. 2010, 31, 455-461. [CrossRef]

16. Mark, P.; Nilsson, L. Structure and Dynamics of the TIP3P, SPC, and SPC/E Water Models at 298 K. J. Phys. Chem. A 2001, 105, 9954-9960. [CrossRef]

17. Mayer, M.; Meyer, B. Characterization of Ligand Binding by Saturation Transfer Difference NMR Spectroscopy. Angew. Chem. Int. Ed. Engl. 1999, 38, 1784-1788. [CrossRef]

18. Dalvit, C.; Fogliatto, G.; Stewart, A.; Veronesi, M.; Stockman, B. WaterLOGSY as a method for primary NMR screening: Practical aspects and range of applicability. J. Biomol. NMR 2001, 21, 349-359. [CrossRef]

19. Jansen, S.; Collins, A.; Yang, C.; Rebowski, G.; Svitkina, T.; Dominguez, R. Mechanism of actin filament bundling by fascin. J. Biol. Chem. 2011, 286, 30087-30096. [CrossRef]

20. Boukamp, P.; Petrussevska, R.T.; Breitkreutz, D.; Hornung, J.; Markham, A.; Fusenig, N.E. Normal keratinization in a spontaneously immortalized aneuploid human keratinocyte cell line. J. Cell Biol. 1988, 106, 761-771. [CrossRef]

21. Jelassi, B.; Chantôme, A.; Alcaraz-Pérez, F.; Baroja-Mazo, A.; Cayuela, M.L.; Pelegrin, P.; Surprenant, A.; Roger, S. P2X(7) receptor activation enhances SK3 channels- and cystein cathepsin-dependent cancer cells invasiveness. Oncogene 2011, 30, 2108-2122. [CrossRef]

22. Fior, R.; Póvoa, V.; Mendes, R.V.; Carvalho, T.; Gomes, A.; Figueiredo, N.; Ferreira, M.G. Single-cell functional and chemosensitive profiling of combinatorial colorectal therapy in zebrafish xenografts. Proc. Natl. Acad. Sci. USA 2017, 114, E8234-E8243. [CrossRef]

23. Albini, A. Tumor and endothelial cell invasion of basement membranes. The matrigel chemoinvasion assay as a tool for dissecting molecular mechanisms. Pathol. Oncol. Res. 1998, 4, 230-241. [CrossRef] [PubMed]

24. Nowak-Sliwinska, P.; Scapozza, L.; Ruiz i Altaba, A. Drug repurposing in oncology: Compounds, pathways, phenotypes and computational approaches for colorectal cancer. Biochim. Biophys. Acta Rev. Cancer 2019, 1871, 434-454. [CrossRef] [PubMed] 
25. Carleo, M.A.; Di Martino, F.; Del Giudice, A.; Gargiulo, M.; Parrella, G.; Rosario, P.; Sangiovanni, V.; Viglietti, R.; Esposito, V.; Chirianni, A. Different impact of anti-retroviral regimen containing protease inhibitors on development of HIV-related Kaposi sarcoma. Vivo 2015, 29, 133-136.

26. Singh, I.R.; Gorzynski, J.E.; Drobysheva, D.; Bassit, L.; Schinazi, R.F. Raltegravir is a potent inhibitor of XMRV, a virus implicated in prostate cancer and chronic fatigue syndrome. PLoS ONE 2010, 5, e9948. [CrossRef] [PubMed]

27. Chang, Y.C.; Chiou, J.; Yang, Y.F.; Su, C.Y.; Lin, Y.F.; Yang, C.N.; Lu, P.J.; Huang, M.S.; Yang, C.J.; Hsiao, M. Therapeutic Targeting of Aldolase A Interactions Inhibits Lung Cancer Metastasis and Prolongs Survival. Cancer Res. 2019, 79, 4754-4766. [CrossRef]

28. Scanlon, K.J.; Kashani-Sabet, M.; Sowers, L.C. Overexpression of DNA replication and repair enzymes in cisplatin-resistant human colon carcinoma HCT8 cells and circumvention by azidothymidine. Cancer Commun. 1989, 1, $269-275$.

29. Oprea, T.I.; Bauman, J.E.; Bologa, C.G.; Buranda, T.; Chigaev, A.; Edwards, B.S.; Jarvik, J.W.; Gresham, H.D.; Haynes, M.K.; Hjelle, B.; et al. Drug Repurposing from an Academic Perspective. Drug. Discov. Today Strateg. 2011, 8, 61-69. [CrossRef]

30. Zhang, Y.; Lu, Y.; Zhang, C.; Huang, D.; Wu, W.; Shen, J.; Cai, Y.; Chen, W.; Yao, W. FSCN-1 increases doxorubicin resistance in hepatocellular carcinoma through promotion of epithelial-mesenchymal transition. Int. J. Oncol. 2018, 52, 1455-1464. [CrossRef] [PubMed]

31. Ghebeh, H.; Al-Khaldi, S.; Olabi, S.; Al-Dhfyan, A.; Al-Mohanna, F.; Barnawi, R.; Tulbah, A.; Al-Tweigeri, T.; Ajarim, D.; Al-Alwan, $\mathrm{M}$. Fascin is involved in the chemotherapeutic resistance of breast cancer cells predominantly via the PI3K/Akt pathway. Br. J. Cancer 2014, 111, 1552-1561. [CrossRef]

32. Mohr, C.F.; Gross, C.; Bros, M.; Reske-Kunz, A.B.; Biesinger, B.; Thoma-Kress, A.K. Regulation of the tumor marker Fascin by the viral oncoprotein Tax of human T-cell leukemia virus type 1 (HTLV-1) depends on promoter activation and on a promoterindependent mechanism. Virology 2015, 485, 481-491. [CrossRef]

33. Yu, F.L.; Miao, H.; Xia, J.; Jia, F.; Wang, H.; Xu, F.; Guo, L. Proteomics Analysis Identifies IRSp53 and Fascin as Critical for PRV Egress and Direct Cell-Cell Transmission. Proteomics 2019, 19, e1900009. [CrossRef]

34. Mohr, C.F.; Kalmer, M.; Gross, C.; Mann, M.C.; Sterz, K.R.; Kieser, A.; Fleckenstein, B.; Kress, A.K. The tumor marker Fascin is induced by the Epstein-Barr virus-encoded oncoprotein LMP1 via NF- $\mathrm{kB}$ in lymphocytes and contributes to their invasive migration. Cell Commun. Signal. 2014, 12, 46. [CrossRef]

35. Mosialos, G.; Yamashiro, S.; Baughman, R.W.; Matsudaira, P.; Vara, L.; Matsumura, F.; Kieff, E.; Birkenbach, M. Epstein-Barr virus infection induces expression in B lymphocytes of a novel gene encoding an evolutionarily conserved 55-kilodalton actin-bundling protein. J. Virol. 1994, 68, 7320-7328. [CrossRef]

36. Gong, L.P.; Chen, J.N.; Xiao, L.; He, Q.; Feng, Z.Y.; Zhang, Z.G.; Liu, J.P.; Wei, H.B.; Shao, C.K. The implication of tumor-infiltrating lymphocytes in Epstein-Barr virus-associated gastric carcinoma. Hum. Pathol. 2019, 85, 82-91. [CrossRef] [PubMed]

37. Al-Antary, N.; Farghaly, H.; Aboulkassim, T.; Yasmeen, A.; Akil, N.; Al Moustafa, A.E. Epstein-Barr virus and its association with Fascin expression in colorectal cancers in the Syrian population: A tissue microarray study. Hum. Vaccines Immunother. 2017, 13, 1573-1578. [CrossRef] [PubMed]

38. Said, J.W.; Pinkus, J.L.; Yamashita, J.; Mishalani, S.; Matsumura, F.; Yamashiro, S.; Pinkus, G.S. The role of follicular and interdigitating dendritic cells in HIV-related lymphoid hyperplasia: Localization of fascin. Mod. Pathol. 1997, 10, 421-427.

39. Xiao, P.; Liu, W.; Zhou, H. miR-200b inhibits migration and invasion in non-small cell lung cancer cells via targeting FSCN1. Mol. Med. Rep. 2016, 14, 1835-1840. [CrossRef]

40. Yang, X.; Lei, P.; Huang, Y.; Zhang, Z.; Zhang, Y. MicroRNA-133b inhibits the migration and invasion of non small cell lung cancer cells via targeting FSCN1. Oncol. Lett. 2016, 12, 3619-3625. [CrossRef] [PubMed]

41. Zhang, Y.; Yang, X.; Wu, H.; Zhou, W.; Liu, Z. MicroRNA-145 inhibits migration and invasion via inhibition of fascin 1 protein expression in non-small-cell lung cancer cells. Mol. Med. Rep. 2015, 12, 6193-6198. [CrossRef] [PubMed]

42. Wang, N.; Zhang, T. Downregulation of MicroRNA-135 Promotes Sensitivity of Non-Small Cell Lung Cancer to Gefitinib by Targeting TRIM16. Oncol. Res. 2018, 26, 1005-1014. [CrossRef] [PubMed]

43. Lin, S.; Huang, C.; Gunda, V.; Sun, J.; Chellappan, S.P.; Li, Z.; Izumi, V.; Fang, B.; Koomen, J.; Singh, P.K.; et al. Fascin Controls Metastatic Colonization and Mitochondrial Oxidative Phosphorylation by Remodeling Mitochondrial Actin Filaments. Cell Rep. 2019, 28, 2824-2836.e2828. [CrossRef] [PubMed] 